\title{
A Double-labeling Investigation of the Afferent Connectivity to Cortical Areas V1 and V2 of the Macaque Monkey ${ }^{1}$
}

\author{
H. KENNEDY² AND J. BULLIER
}

Laboratoire de Neuropsychologie Expérimentale, Institut National de la Santé et de la Recherche Médicale, Unité 94,16 avenue Doyen Lépine, Г-69500 Bron, Trance

\begin{abstract}
The afferent connectivity of areas V1 and V2 was investigated using the fluorescent dyes fast blue and diamidino yellow. Simultaneous injection of each dye in retinotopically corresponding regions of these areas gave rise to two afferent populations of labeled neurons in subcortical and cortical structures which project to both areas. These two populations showed a variable degree of overlap in their spatial distribution. Neurons labeled by both dyes (double-labeled neurons) which, therefore, project to both areas, were found in substantial numbers in these overlap zones. When the injections were made in non-retinotopically corresponding regions in the two areas, both populations of labeled cells overlapped extensively in the cortex but not in subcortical structures, suggesting that the laws governing the topography of these two types of connections are different.

In the cortex, the labeled neurons extended from the fundus of the lunate sulcus to the fundus of the superior temporal sulcus. A few labeled neurons were also found in the inferior temporal cortex and the parahippocampal gyrus. In all cortical regions, corticocortical neurons projecting to $\mathrm{V} 1$ and $V 2$ were found in both supra- and infragranular layers, although double-labeled neurons were more numerous in infragranular layers. With increasing distance from $V_{1}$ there was an increase in the proportion of neurons labeled in infragranular layers. The comparative strength of input to $V_{1}$ and $V_{2}$ was computed and was found to be higher to V2 in all cortical regions except the superior temporal sulcus which projected equally heavily to both areas. The superior temporal sulcus also stood out in that of all cortical regions it contained the highest proportion of double-labeled neurons.

Single- and double-labeled neurons were found in a number of subcortical structures including the lateral geniculate nucleus, the inferior and lateral pulvinar, the intralaminar nuclei, the nucleus basalis of Meynert, and the amygdala. The pattern of labeling in the lateral pulvinar was in agreement with the suggestion that this structure has a complex topographical organization containing at least a dual representation of the visual field (Bender, D. B. (1981) J. Neurophysiol. 46: 672-693). In the pulvinar complex, densities of
\end{abstract}

Received January 18, 1985; Revised March 25, 1985

Accepted March 27, 1985

\footnotetext{
We thank Noëlle Boyer and Pascale Giroud for their technical expertise, Séverin Bello for photographic work, and Michelle Rouvière for typing the manuscript. Funding by Ministère de la Recherche et Technologie Grant 83.C.0907 is gratefully acknowledged.

${ }^{2}$ To whom correspondence should be addressed.
}

labeled neurons permitted evaluation of the strength of input to $V 1$ and V2, the latter being the strongest.

These results demonstrate that areas $V 1$ and $V_{2}$ share a vast amount of common input from the same cortical and subcortical structures and that a number of neurons project to both areas via branching axons.

Since the discovery of multiple representations of the visual field on the mammalian cortical surface (Van Essen, 1979; Kaas, 1980; Tusa et al., 1981), numerous studies have addressed the question of their afferent connectivity. Anterograde and retrograde tracing techniques have demonstrated extensive redundancy in the connections of these visual areas. In other words, each area receives from several subcortical nuclei and cortical areas (see review in Bullier, 1985). The use of dual retrograde tracing techniques has allowed a more precise comparison between the afferents to two cortical areas. In particular, it has been shown in the cat that areas 17,18 , and 19 receive a vast amount of common input from subcortical and cortical structures and that there is no subdivision according to cortical target in these structures (Bullier et al., 1984a, b). It has also been possible to demonstrate the presence of numerous axonal bifurcations in the afferents to these cortical visual areas (Bullier et al., 1984a, b).

The large amount of common input to different visual areas and the ubiquity of axonal bifurcation in these connections show that there is a far greater degree of distribution of information to the different visual cortical areas of the cat than was previously believed. This raises the question of the extent to which this organizational principle is a general one, or whether it is limited to the cat visual system. To distinguish between these two possibilities, we have examined the relative distribution and axonal bifurcation of the afferents to areas $\mathrm{V} 1$ and $\mathrm{V} 2$ in the macaque monkey. The principal reason for this choice is that, contrary to the cat in which the lateral geniculate nucleus (LGN) projects to numerous cortical areas (Maciewicz, 1975; Hollander and Vanegas 1977; Geisert, 1980), the projection from this nucleus in the macaque monkey is much more focused. Practically all neurons in the main laminae project to V1 and only a sparse projection originating from a few cells, mostly located between these LGN laminae, project to extrastriate visual areas (Benevento and Yoshida 1981; Fries 1981; Yukie and Iwai, 1981; Bullier and Kennedy 1983). The greater segregation of the LGN afferents to $V 1$ and $V 2$ found in the macaque could be paralleled by those originating from the pulvinar or from other cortical areas. We have therefore approached this question by making paired injections in retinotopically corresponding regions of V1 and V2 and examining the relative distribution of back-labeled neurons and the proportion of double-labeled cells. 
Our choice of $V_{1}$ and $V_{2}$ in the macaque was motivated at least partially by the fact that these areas are generally considered as constituting two different stages in the cortical processing of information coming from the LGN. Ihis stems from the fact that, as mentioned above, the LGN projects mostly to $\mathrm{V} 1$ and that $\mathrm{V} 2$ depends on V1 for its visual activation (Schiller and Malpeli, 1977). Here again, the situation in the macaque monkey is quite different from that observed in the cat, where areas 17, 18, and 19 function largely independently from each other (Donaldson and Nash, 1975; Dreher and Cottee, 1975; Sherk, 1978; Kimura et al., 1980). It was therefore of primary interest to determine whether two adjacent cortical areas representing different stages in the processing of sensory information also share a large amount of afferent input.

in our previous study of afferent connections to visual cortical areas by the double-labeling technique (Bullier et al., 1984a, b), we found that double-labeled neurons were nearly always restricted to the region of overlap of the two populations of single-labeled neurons. We concluded from this observation that the two branches of a bifurcating axon terminate in cortical regions representing the same portion of the visual field. Since then, several experimental results have led us to revise this interpretation. In some doublelabeling experiments on the cat, where retinotopic correspondence between injections was poor, we nonetheless found cortical regions of overlap of the two populations of cells as well as double-labeled neurons. Similarly, when two injections are made side-by-side within a cortical area, it is possible to observe, in afferent cortical areas, overlap of the populations of single-labeled neurons and doublelabeled neurons in this region, despite the lack of overlap of the populations of single-labeled cells in the thalamus (D. J. Perkel, J. Bullier, and $\mathrm{H}$. Kennedy, unpublished results). These findings show that double-labeled neurons and overlap of single-labeled populations do not only result from injections in retinotopically corresponding regions, suggesting that cortical connectivity is poorly retinotopically organized due to a high degree of divergence in cortical efferents. In this report we have directly addressed the issue of divergence of cortical connections by comparing those results obtained when the paired injections were made in retinotopic regions with those obtained following injections in non-retinotopic corresponding regions.

\section{Materials and Methods}

Injections of the fluorescent tracers diamidino yellow (DY; $3 \%$ ) and fast blue (FB; $3 \%$ ) were made with Hamilton syringes in eight adult cynomolgus monkeys (Macaca irus) anesthetized with ketamine hydrochloride $(15 \mathrm{mg} /$ $\mathrm{kg}$, i.m.) and chlorpromazine (2 $\mathrm{mg} / \mathrm{kg}$, i.m.) followed by pentobarbitone sodium ( 5 to $15 \mathrm{mg} / \mathrm{kg}$, i.v.) or alfaxolone-alfadolone. Six animals were given a single injection of one fluorescent dye in V1 and the other dye in V2 (Table 1). The injections were made in such a way that each included a region representing a common part of the visual field (Gattass et al., 1981). The injections in $V 1$ were made on the operculum at some distance $(4$ to $6 \mathrm{~mm}$ ) posterior and parallel to the entrance of the lunate sulcus. The injection was made at a shallow angle to the cortical surface so that it could span 4 to 6 $\mathrm{mm}$ in the gray matter. The $\mathrm{V} 2$ injections were made perpendicular to the horizontal Horsley Clarke plane and extended 4 to $6 \mathrm{~mm}$ down the posterior bank of the lunate sulcus. As the syringe was retracted, 0.05 to $0.1 \mu \mathrm{l} / \mathrm{mm}$ of the dye was injected.

Three animals received paired injections of FB and DY in V1 separated by 1.9 to $2.2 \mathrm{~mm}$ (Table I). In two of these animals (BKO6 and BKO9) the injections were made approximately normal to the cortex and 4 to $6 \mathrm{~mm}$ posterior to the lunate sulcus. In one animal (BKO13) both injections were made parallel to the lunate sulcus and at a shallow angle to the cortical surface so that they spanned approximately $5 \mathrm{~mm}$ of cortex. In this animal both $V 1$ injections had configurations similar to those in the animals in which $\mathrm{V} 1$ and $\mathrm{V} 2$ were injected.

The animals were recovered and, after a survival period of 7 to 12 days, were deeply anesthetized and perfused transcardially with $200 \mathrm{ml}$ of $2.7 \%$ saline, followed by 3 liters of $30 \%$ formalin in $0.1 \mathrm{M}$ cacodylate buffer, 1 liter of $8 \%$ sucrose, 1 liter of $20 \%$ sucrose, and 1 liter of $30 \%$ sucrose in cacodylate buffer. The brain was immediately removed, blocked, and cut on a freezing microtome at $40 \mu \mathrm{m}$, every third section being kept. Horizontal sections were made of the occipital lobe, extending up to and including the
TABIF I

Experimental cases, survival times, and dyes injected

\begin{tabular}{lccc}
\hline Cases & Dyes Injected & Survival Times & Remarks \\
\hline BKO1 & DY in V1 & 7.5 & DY injection encroached \\
& FB in V2 & days & on V1-V2 border
\end{tabular}

$\mathrm{BKO} 2$

$\mathrm{FB}$ in $\mathrm{V} 1$

9.4

DY in $V 2$

days

FB injection encroached on 1 -V2 border

BKO4 FB in V1 11 days good injections
DY in $V 2$

$\begin{aligned} & \text { BKO5 } \text { FB in V1 } \\ & \text { DY in V2 }\end{aligned}$

11 days good injections poor retinotopic corre spondence

BKO6 2 injections in $V 1 \quad 7$ days good injections

BKO9

Right hemi- 2 injections in V1 11 days FB injections encroached sphere

Left hemi$1.9 \mathrm{~mm}$ separ DY in $\mathrm{V} 1$ sphere $\mathrm{FB}$ in $\mathrm{V} 2$

11 days FB injections invaded an terior bank of lunate sulcus

BKO12 $\quad$ FB in $V 1$ days good injections
DY in $V 2$

BKO13 2 injections in $V 1 \quad 12$ days good injections $2.2 \mathrm{~mm}$ separ.

fundus of the superior temporal sulcus. The rest of the brain, including the thalamus, was cut in a frontal plane. Sections were mounted from saline onto gelatinized slides and observed in UV light using a Leitz fluorescence microscope with a $D$ filter set ( 355 to $425 \mathrm{~nm}$ ). The properties and description of DY- and FB-labeled neurons can be found in a recent publication by Kuyper's group (Keizer et al., 1983). FB-labeled neurons exhibit a blue coloration in their cytoplasm and DY-labeled neurons exhibit a yellow nucleus. Double-labeled neurons simultaneously show a DY-positive nucleus and an FB-positive cell body. Sections were traced and the position of labeled neurons was recorded by means of an $X-Y$ plotting table electronically coupled to the microscope stage. Those cortical and subcortical regions containing maximum numbers of doublc labcled neurons were chosen for quantification. Counts were made of the three populations of back-filled cells (DY-positive, FB-positive, and double-labeled neurons) in the region of overlap of the two populations of single-kabeled reuruns. Lankmarks such as a pial border and blood vessels were outlined. Sections were then counterstained (Nissl and myelin stains) and projected onto the plots of labeled neurons so as to determine histological borders.

\section{Results}

Technical considerations. In order to interpret double-labeled neurons as having axons which bifurcate and terminate in the two injected regions, one must be able to delimit the zones of uptake in the cortex: spillover of the dyes between injection sites or into adjacent areas could give rise to double-labeling of cells which do not necessarily send collaterals to the two intended cortical sites.

A direct indication of the size of the uptake zone in the cortex is provided by examination of the injection site itselt. The extent of locally labeled cells is characteristic for each cortical lamina. In layers $2 / 3$ and $5 / 6$ which, in $V 1$ and $V 2$, are known to have long lateral connections (Lund, 1973; Fisken et al., 1975; Lund et al., 1981), labeled cells extend as far as several millimeters from the needle track. Layer 4, which has very limited lateral connectivity (Lund, 1973; Lund et al., 1981), shows labeled cells only very near to the needle track (see Figs. 2 and 3; see also Fig. 1 in Bullier and Kennedy, 1983). These observations suggest that the region of uptake is smaller than the region of locally labeled cells in layer 4

So as to make an estimation of the uptake zone of the dyes, we have made adjacent injections of FB and DY in area 17 and 
examined the disposition of the two populations of back-filled cells in the LGN. Previous work in the cat visual cortex showed that superimposition of the two injections gave rise to almost total overlap in the two afferent populations in the LGN together with large numbers of double-labeled cells (Bullier et al., 1984a). In contrast two adjacent and nonoverlapping columns of retrograde labeled cells in the LGN were obtained in the cat when the injection sites were separated by $2 \mathrm{~mm}$. We have replicated these experiments in three monkeys. DY and FB were injected in area 17 in two long parallel injections ( 4 to $6 \mathrm{~mm}$ long, $0.5 \mu$ l of each dye). Each injection was made at a shallow angle with respect to the cortical surface and the injections were separated by about $2 \mathrm{~mm}$ (Table I). In all cases we observed two separate columns of DY- and FB-labeled cells in the LGN. An example is shown in Figure 1, where the columns of labeled cells in frontal sections of the LGN are shown together with a diagram of the injection sites. (Note that these appear on the figure to be separated by $3.2 \mathrm{~mm}$ because the brain was cut at approximately $45^{\circ}$ with respect to the orientation of the injection tracks.) In the LGN there is very little overlap in the two populations of cells and only one double-labeled cell (marked by a star in Fig. 1). These results demonstrate that the uptake zones in the monkey cortex are comparable to those observed in the cat. In both cases the actual region of uptake is smaller than the region of dense color surrounding the injection needle track (Bullier et al., 1984a). We have therefore used the region of high color density as an upper estimate of the region of uptake.

Although the limited extent of the uptake zone in the cortex has definite advantages for restricting the injection to a single cortical area, it also has some disadvantages. In order to compare the projection to $V_{1}$ and $V 2$ and to estimate the proportion of double-
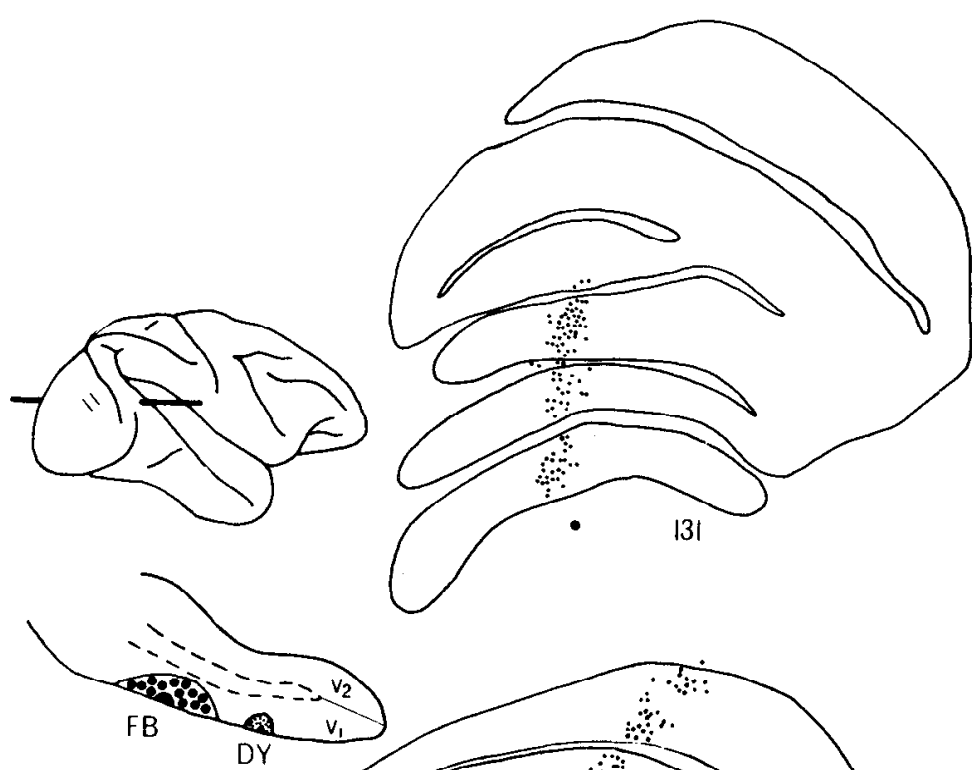

$\underline{2 \mathrm{~mm}}$

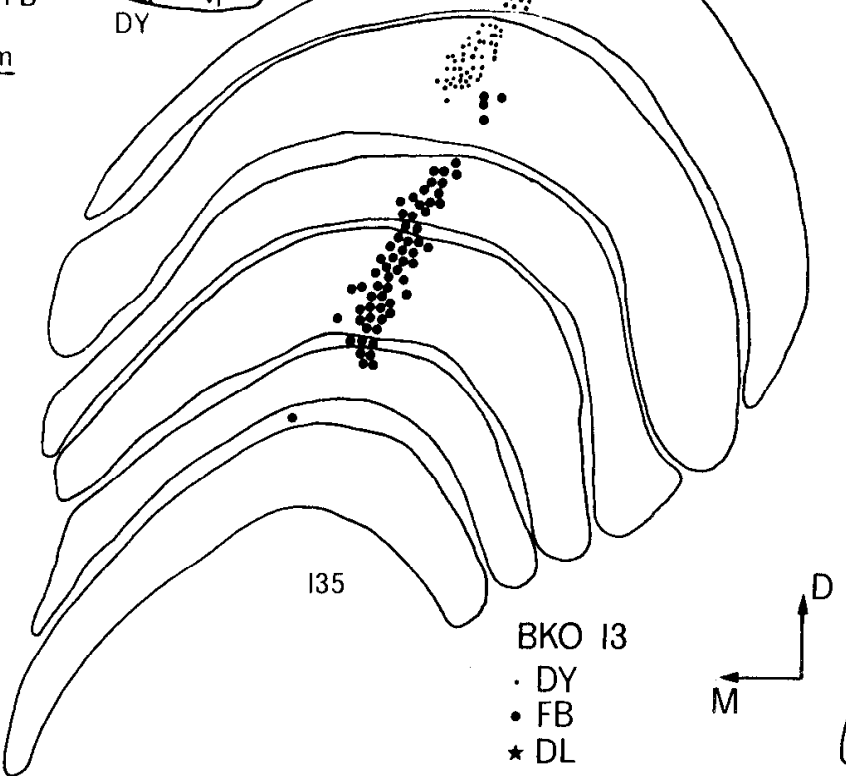

$\mathrm{l} \mathrm{mm}$

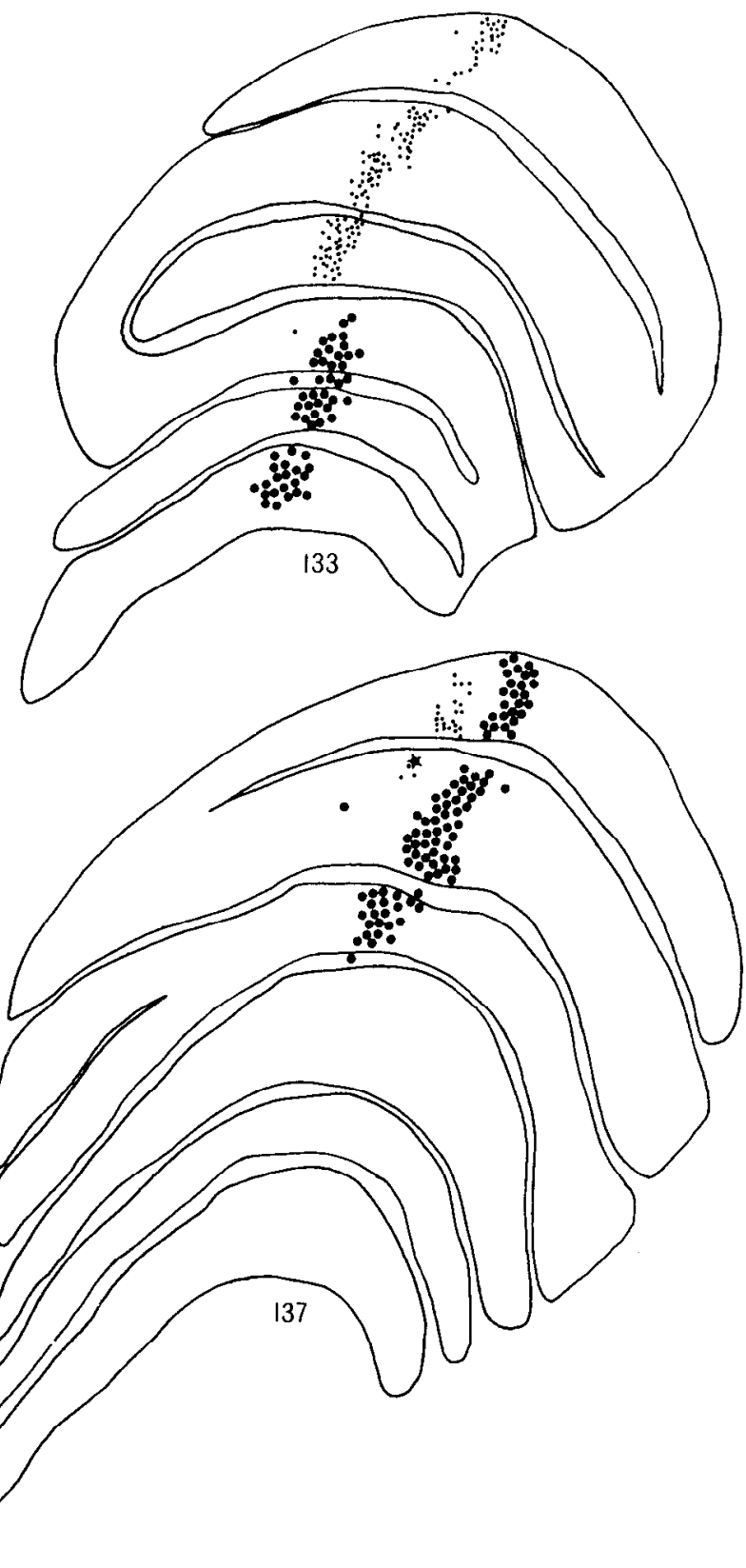

Figure 1. Frontal sections of the LGN (section numbers increase from caudal to rostral) showing populations of FB- and DY-positive neurons after FB and DY injections separated by $2.2 \mathrm{~mm}$ in area 17. The injection sites are indicated by the two parallel lines on the operculum in the lateral view of the brain and the horizontal section shown below. Note that the distance between injection sites is $3.2 \mathrm{~mm}$ on the horizontal section because the plane of cutting makes a $45^{\circ}$ angle with the orientation of the elongated injections. Similar experiments show that the region of cortex where the dye is taken up is less than $2 \mathrm{~mm}$ in diameter (see the text). Large dots, FB-positive neurons; small dots, DY-positive neurons; stars, double-labeled neurons; $M$, medial; $D$, dorsal. 
labeled cells atter injection in $V_{1}$ and $V_{2}$, it is necessary to have overlapping populations of retrogradely labeled cells. This requires that the injections be placed in cortical regions in rough retinotopic correspondence (Bullier et al., 1984a, b), a requirement difficult to meet with dyes which have such limited uptake zones. Adequate retinotopic correspondence of injection sites was achieved by making injections in V1 and V2 which corresponded, in the visual field, to two elongated regions which intercept (see "Materials and Methods").

Description of the injection sites. The purity of the injection sites was checked by examining whether the zorle of dense color surrounding the injection track was restricted to the gray matter of each intended cortical region. An additional control was provided by the pattern of thalamic labeling (see "Discussion").

Confidence in the retinotopic correspondence of the two areas injected can be gained from the relative positions of the back-filled cells from one injection with respect to the needle track of the other. This is illustrated in Figure 2, where each injection site is straddled by back-filled neurons from the injection in the other area. Figure 3 illustrates a case (BKO5) in which the retinotopic correspondence was poor as revealed by the small amount of register between labeled cells and injection sites.

The pattern of labeling in the thalamus and the histological examination of the injection sites showed that, of the six monkeys which received paired injections in $V_{1}$ and $V 2$ (Table $\mathrm{I}$ ), in three (BKO4, BKO5, and BKO12), the uptake zone for each dye was restricted to the intended area. In two animals (BKO4 and BKO12), the uptake zone in each area included regions in retinotopic corre-
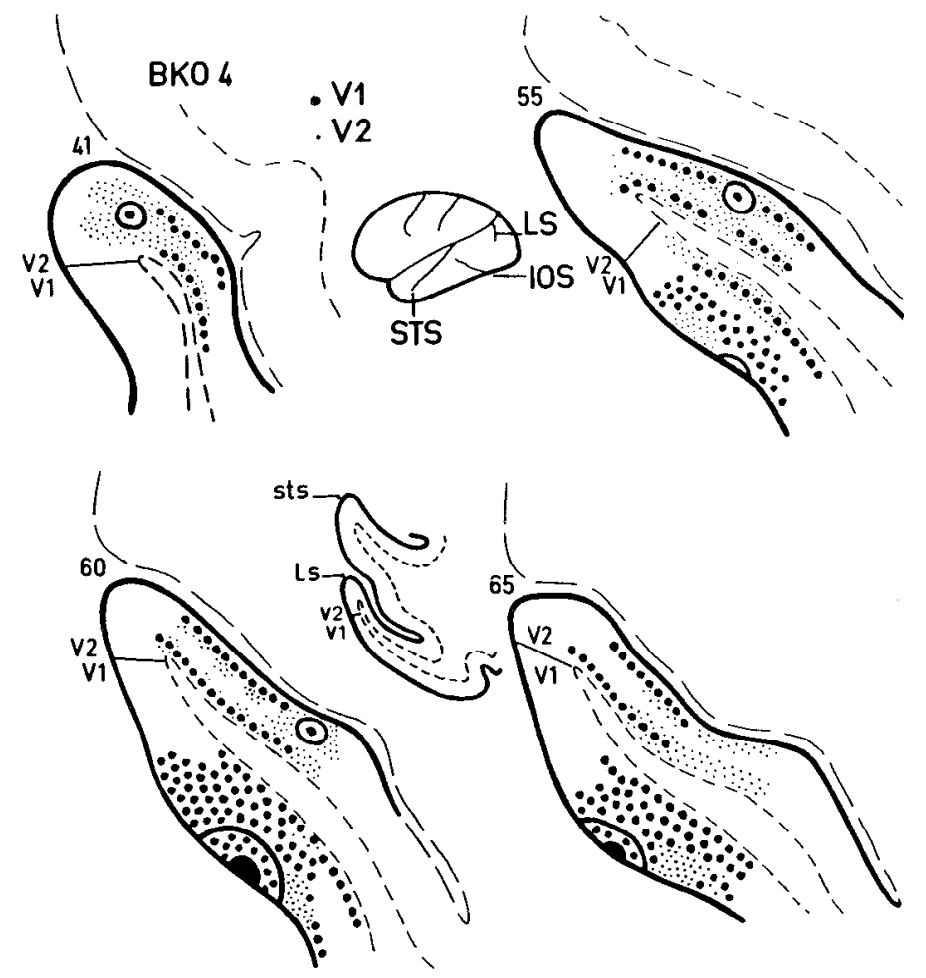

\section{$\underline{2 \mathrm{~mm}}$}

Figure 2. Horizontal sections through $V_{1}$ and $V_{2}$ showing the injection sites in BKO4. The black area represents the needle track and the region enclosed by the heavy line corresponds to the maximum region of uptake of fluorescent dye (zone of high color density). Large dots represent the distribution of labeled cells from injection in $V_{1}$; small dots represent cells labeled by the dye injected in V2. Higher section numbers represent more ventral levels. Note the rather good correspondence between each injection site and the distribution of neurons labeled by the other injection. $1 O S$, inferior occipital sulcus; LS, lunate sulcus; STS, superior temporal sulcus.

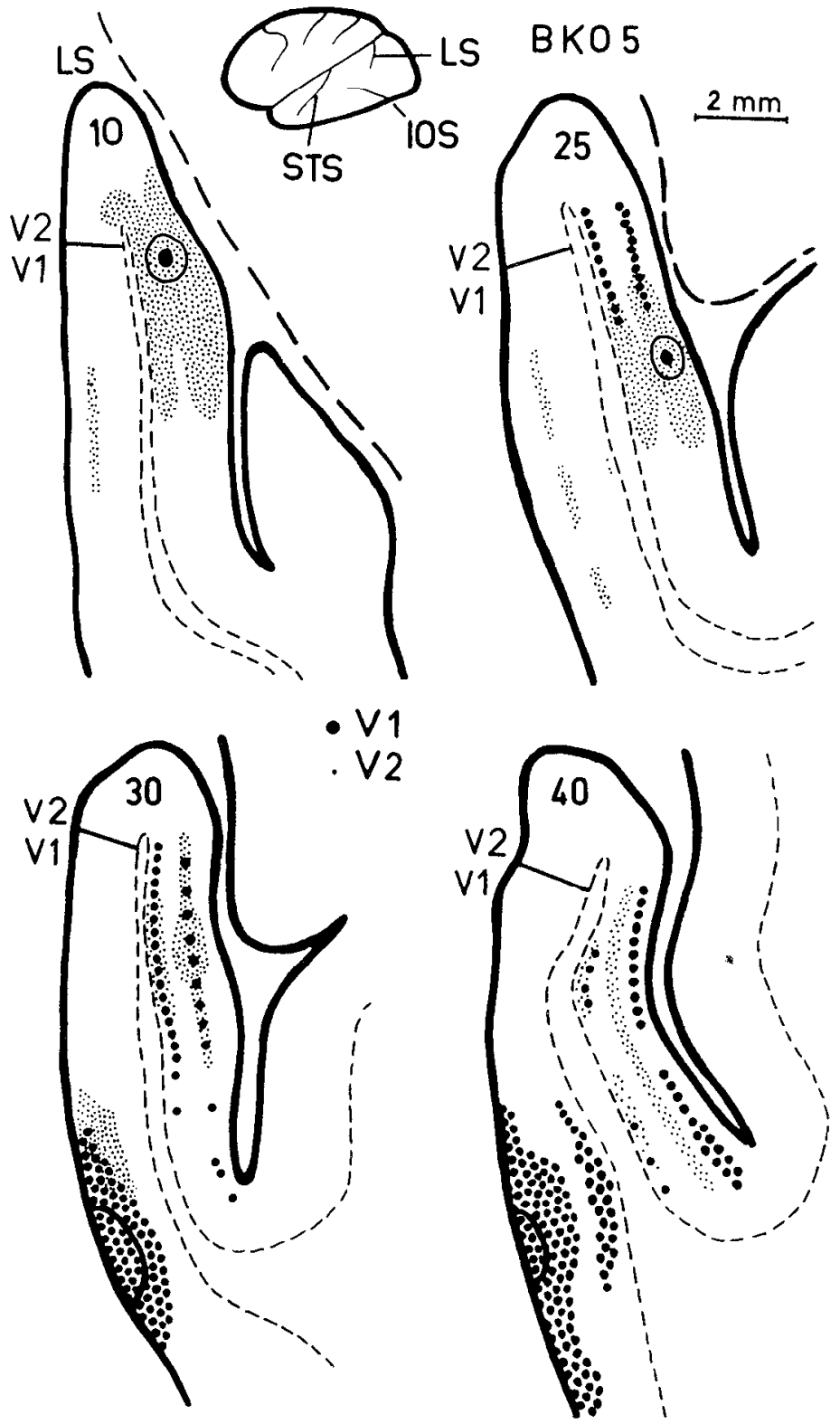

Figure 3. Horizontal sections showing the injections in $V_{1}$ and $V_{2}$ in BKO5. Same conventions as in Figure 2. Note the limited amount of overlap between each injection site and the population of neurons labeled by the other injection.

spondence and, in these animals, quantitative estimations of the numbers of labeled cells were undertaken. In three other animals (BKO1, BKO2, and BKO9) there was a slight encroachment of one of the injections on the V1/N2 border. Results obtained from these animals have been used as supportative data with regard to those questions requiring the presence of a single label.

Distribution of labeled cells in extrastriate visual cortex. Following irijections in V1 and V2 similar to those described in Figures 2 and 3 , retrograde labeled cells were found in an extensive region of cortex anterior to the fundus of the lunate sulcus, including the anterior bank of the lunate sulcus, the prelunate gyrus, and the posterior bank and fundus of the superior temporal sulcus. A small number of labeled neurons was also found in the inferior temporal cortex and the parahippocampal gyrus. When the distribution of cells was plotted on horizontal sections of the brain (Figs. 4 and 5), the territory containing back-labeled cells did not show any obvious discontinuities. As one goes from one section to the next, the 

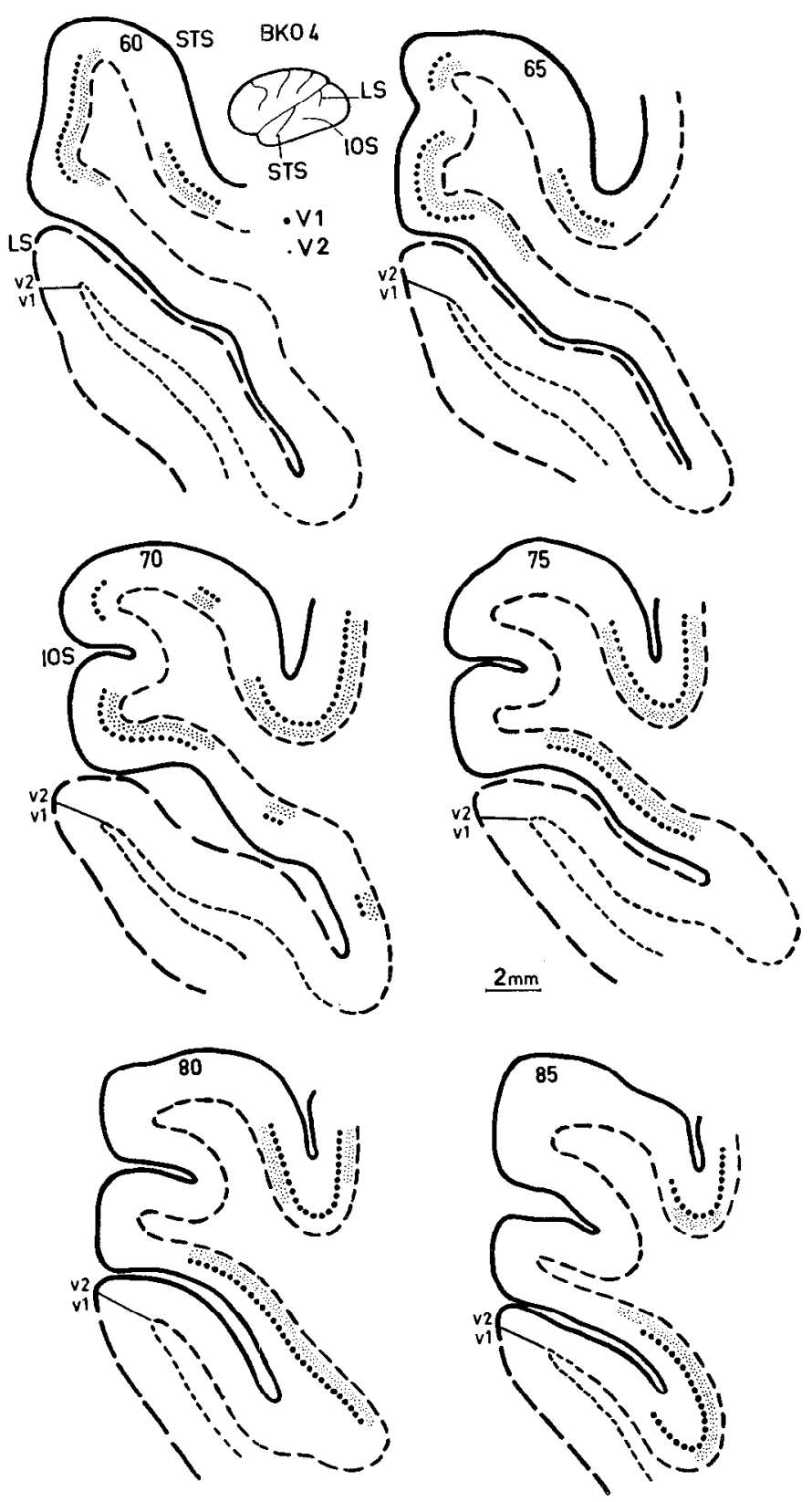

Figure 4. Horizontal sections showing the distribution of labeled cells in prestriate cortex beyond $\mathrm{V} 2$ after the injections in $\mathrm{V} 1$ and $\mathrm{V} 2$ shown in Figure 2. Large dots, distribution of labeled cells resulting from injection in $\mathrm{V} 1$; small dots, distribution of labeled cells resulting from injection in V2. The exact position in the depth of cortex of labeled cells is not shown in this figure. Other conventions are as in Figure 2. Note the good correspondence between the spatial distribution of both populations of labeled cells.

densities of labeled neurons show important modulations in different cortical regions, but it was extremely difficult to find consistent gaps going through successive sections which would have indicated the presence of a focus of labeled cells (see Figs. 4, 5, 8, 9, and 10). This and the absence of electrophysiological mapping or data on callosal connectivity prevented us from analyzing our results in terms of functional visual areas such as V3, V3A, and V4 as these areas are still poorly defined anatomically (Van Essen and Zeki, 1978). We have therefore used gross morphological landmarks such as the sulci and gyri to describe the location of labeled neurons in our material. Broadly speaking, at the horizontal levels where we found labeled cells, the anterior bank of the lunate sulcus contains V3 and V3A, whereas the prelunate gyrus mostly contains V4 (Van Essen and Zeki, 1978). In contrast, we have checked that the group of labeled cells in the fundus and posterior bank of the superior temporal sulcus corresponds to area MT, as identified on myelinstained sections (Van Essen et al., 1981).

Generally, the retinotopic correspondence of the injection sites was not critical to obtain partially overlapping populations of labeled cells in the cortex. This is shown in BKO5 (Fig. 5), in which a substantial amount of overlap is present in the two populations of labeled cells in the cortex despite poor retinotopic correspondence of the injections (Fig. 3). This situation in the cortex contrasted with observations in the pulvinar and claustrum (see below).

The geometrical configuration of the paired injections is such as to include equivalent zones of uptake in $V 1$ and $V 2$ which are therefore connected to those regions of afferent structures where there is an overlap of the two populations of back-filled cells. The strength of the projection to each area can therefore be deduced from the number of retrograde labeled neurons of each population in the region of overlap, given that the pick-up and transport characteristics of the two dyes are grossly equivalent (Bullier and Kennedy, 1983; Bullier et al. 1984a, b; see also "Discussion"). This comparison is presented in Table II and Figure 11 in histogram form. Clearly the projections from the anterior bank of the lunate sulcus and the prelunate gyrus are much stronger to $\mathrm{V} 2$ than to $\mathrm{V} 1$.

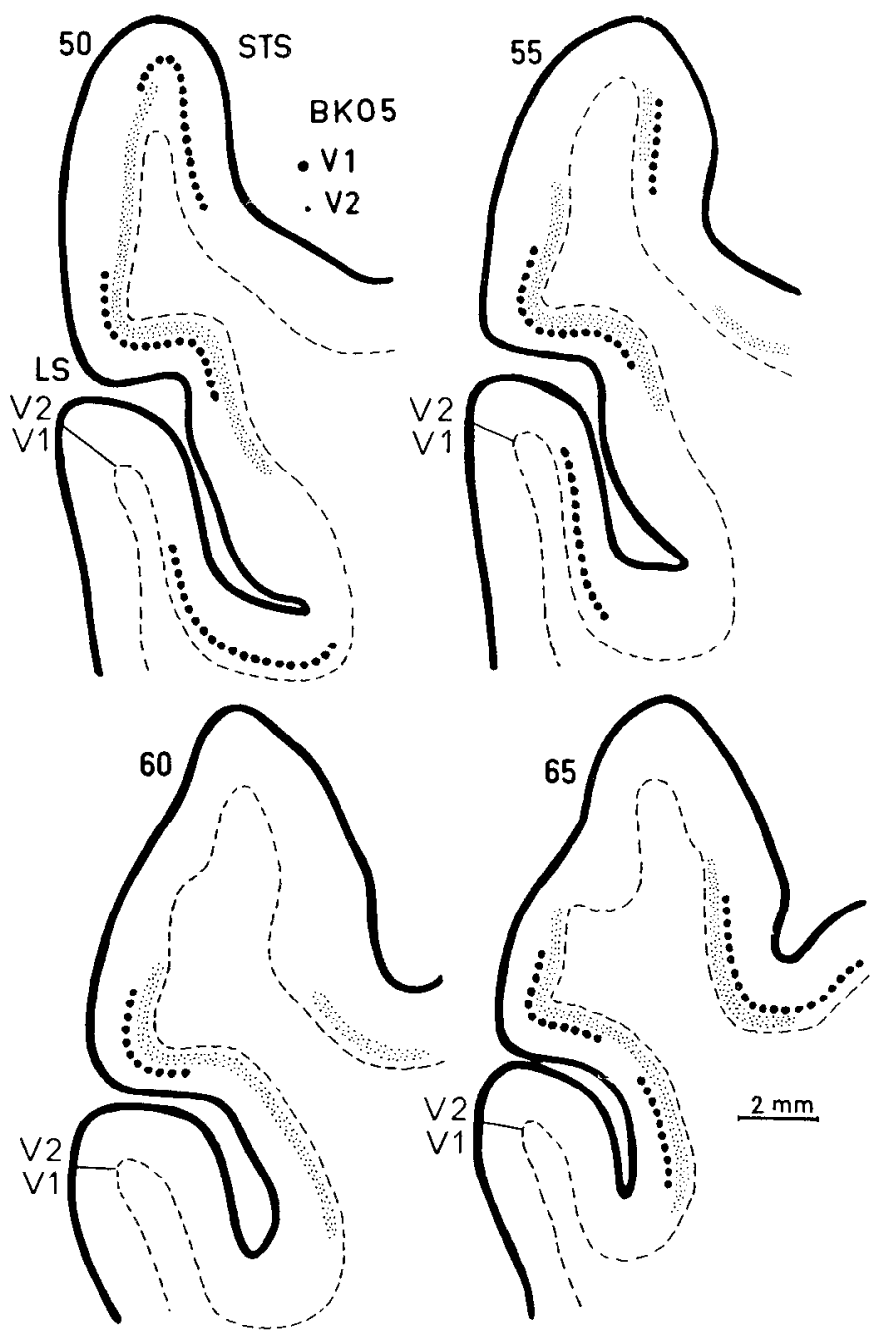

Figure 5. Horizontal sections showing the distribution of labeled neurons in prestriate cortex beyond V2 after the injections shown in Figure 3. Same conventions as in Figure 4. Note the rather good correspondence between the spatial distribution of both populations of labeled neurons despite the poor retinotopic correspondence of the injection sites. 
TABLE ॥

Percentages of neurons in cortical structures projecting to $\mathrm{V} 1, \mathrm{~V} 2$, or V1 and V2 $(\mathrm{V} 1+\mathrm{V} 2)$ via a branching axon

\begin{tabular}{|c|c|c|c|}
\hline Case & Ant. Bank LS & $\mathrm{Pl} \mathrm{G}$ & STS \\
\hline \multirow[t]{3}{*}{ BKO4 } & $V 1,12 \%, N=1637$ & $V 1,17 \%, N=568$ & $V 1,45 \%, N=484$ \\
\hline & V2, $82 \%$ (3 sections) & V2, $80 \%$ ( 2 sections) & V2, $43 \%$ (4 sections) \\
\hline & $V_{1}+V_{2}, 6 \%$ & $V_{1}+V_{2}, 3 \%$ & $V_{1}+V_{2}, 12 \%$ \\
\hline \multirow[t]{3}{*}{ BKO12 } & $V 1,30 \%, N=4938$ & $V 1,38 \%, N=1309$ & $V 1,41 \%, N=971$ \\
\hline & V2, $64 \%$ ( 8 sections) & V2, $54 \%$ (4 sections) & V2, $41 \%$ ( 3 sections) \\
\hline & $v_{1}+v_{2}, 6 \%$ & $V_{1}+V_{2}, 8 \%$ & $V_{1}+V_{2}, 18 \%$ \\
\hline
\end{tabular}

${ }^{a}$ Ant. Bank LS, anterior bank of the lunate sulcus; PLG, prelunate gyrus; STS, superior temporal sulcus.

However, the projections to V1 and V2 from the superior temporal sulcus are of comparable strength.

The heavier projection to V2 from the whole of the prestriate cortcx, exccpt the superior temporal sulcus where the input to both areas is equal, was observed in all experimental animals. In particular, the same observation was made in BKO1 where the dyes injected in V1 and V2 were interchanged with respect to BKO4 and BKO12 (Table I). Despite a small spillover of the V1 injection into V2, which should normally increase the number of cells labeled by the $V 1$ dye, there was still a stronger input to $V 2$ from the anterior bank of the lunate sulcus and the prelunate gyrus and similar numbers of labeled cells in the superior temporal sulcus projecting to either of these areas. This demonstrates that the observed difference in strength of input to $V 1$ and $V 2$ does not arise from different pick-up characteristics of the two dyes.

In the inferior temporal cortex and parahippocampal gyrus, there was a low density of labeled cells, which made it meaningless to determine a zone of overlap of the two populations of marked cells. Both populations appeared to be of similar sizes.

Distribution of labeled cells in cortical laminae. Labeled cells were found in layers $2 / 3$ and $5 / 6$ and only rarely in lamina 4 . In V1, the cells projecting to $\mathrm{V} 2$ were distributed in three bands: one corresponding to layers $2 / 3$, another to layer $4 \mathrm{~B}$, and a third to lower lamina 5 and upper lamina 6 (Fig. 6). The ratio of cells in upper and lower layers was estimated in the zone of maximum uptake and showed that $86 \%$ of the cells in $V 1$ projecting to $V 2$ were in layers $2 / 3$ and $4 \mathrm{~B}$ (Table III). In V2, most of the neurons projecting to $\mathrm{V} 1$ were in laminae 5 and 6 , but a sizable proportion (15 to 22\%) was also found in laminae 2 and 3 (Fig. 7, Table III).

Neurons projecting to $\mathrm{V} 1$ and $\mathrm{V} 2$ in the anterior bank of the lunate sulcus (Fig. 8), the prelunate gyrus (Fig. 9), and the superior temporal sulcus (Fig. 10) were mostly located in deep cortical layers. The proportions of labeled neurons in infragranular layers were computed in the overlap zones (Table III). As one moves away from V2, more and more cells are found in infragranular layers. In the superior temporal sulcus and the inferior temporal cortex (not shown), the proportion of labeled cells in layers 5 and 6 approaches $100 \%$. The laminar location of the corticocortical cells appeared to be similar for neurons of a given area projecting to $\mathrm{V} 1$ or $\mathrm{V} 2$.

Axonal bifurcation in the cortical afferents to $V_{1}$ and $V_{2}$. After paired injections in V1 and V2, double-labeled neurons were found in all cortical regions projecting to these areas. Double-labeled neurons tended to be found almost exclusively in the regions where the two populations of single-labeled neurons overlapped (Figs. 8 to 10).

Quantitative estimation of the proportion of double-labeled neurons for each cortical region is expressed as the percentage of double-labeled neurons within the zone of overlap with respect to the total number of back-labeled neurons. This is provided in table II which shows that the percentage of double-labeled neurons is higher in the superior temporal sulcus (12 to $18 \%$ ) than in the anterior bank of the lunate sulcus and the prelunate gyrus ( 3 to $8 \%$ ).

An alternative to expressing the percentage of double-labeled cells with respect to the total population of labeled cells is to express
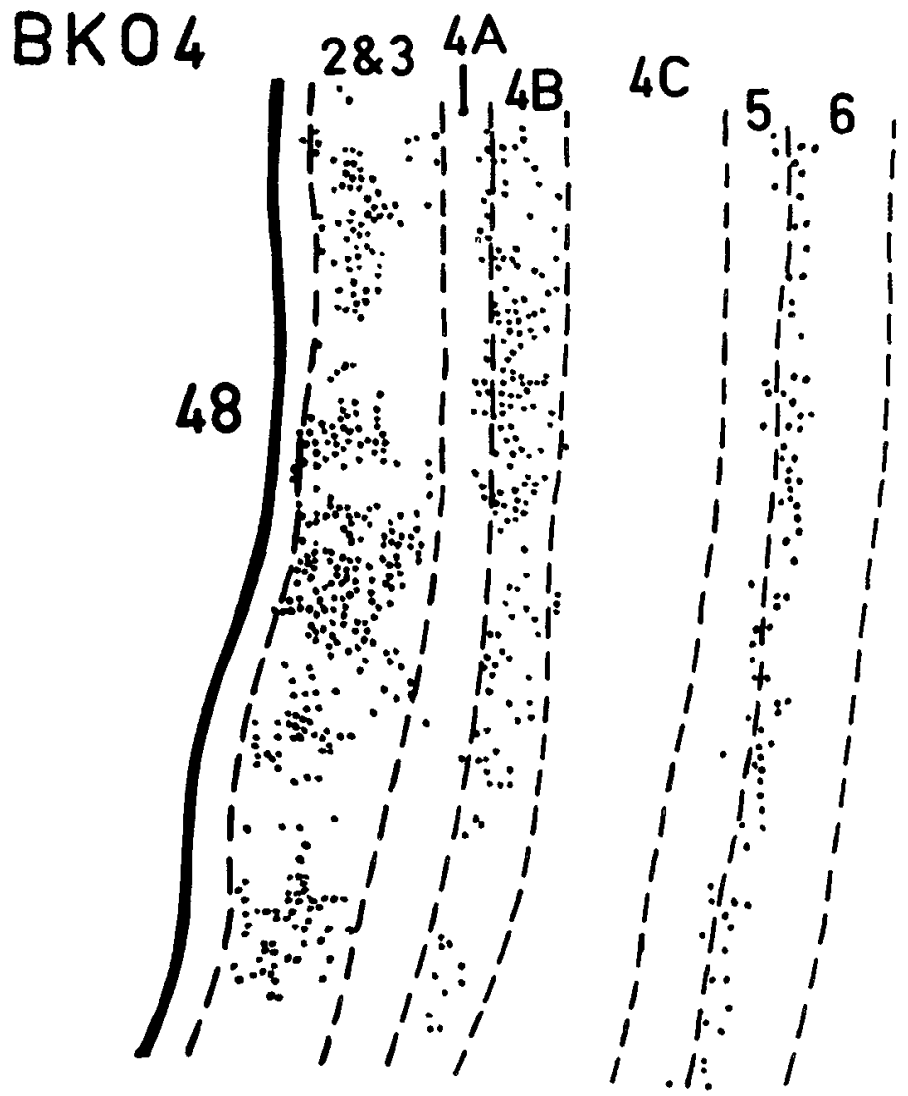

\section{$1 \mathrm{~mm}$}

Figure 6. Laminar distribution of labeled cells in V1 after injection in V2. The number 48 denotes the section number. Other numerals label the different laminae.

it with respect to the population of neurons projecting to one cortical target. When the proportion of cells projecting to one area is much greater than that projecting to the other, as in the case of the neuronal population in the anterior bank of the lunate sulcus and the prelunate gyrus projecting to $V_{2}$, then the two methods of expressing the number of bifurcating neurons can give very different results. For this reason, we have estimated separately the percentage of double-labeled neurons with respect to the population of FB- and DY-labeled neurons. These estimations represent the proportion of neurons projecting to one area (e.g., V1) which also send a collateral to the other injected area (e.g., V2). These percentages are given in Table IV. Of the neurons projecting to $\mathrm{V} 1,16$ to $32 \%$ also send a 
TABLE III

Proportions of neurons projecting to $\mathrm{V} 1$ and/or $\mathrm{V} 2$ which belong to the infragranular layer

\begin{tabular}{|c|c|c|c|c|c|c|}
\hline Case & Projecting to & Neurons in V1 & Neurons in V2 & $\begin{array}{l}\text { Neurons in Ant. } \\
\text { Bank LS } \text { LS }^{a}\end{array}$ & Neurons in PLG & Neurons in STS \\
\hline \multirow[t]{3}{*}{$\mathrm{BKO} 4$} & $V_{1}$ & & $\begin{array}{c}\text { not } \\
\text { counted }\end{array}$ & $\begin{array}{c}71 \% \\
N=183 \\
\text { (3 sections) }\end{array}$ & $\begin{array}{c}77 \% \\
N=96 \\
\text { (2 sections) }\end{array}$ & $\begin{array}{c}96 \% \\
N=216 \\
\text { (4 sections) }\end{array}$ \\
\hline & V2 & $\begin{array}{c}14 \% \\
N=566 \\
(1 \text { section) }\end{array}$ & & $\begin{array}{c}73 \% \\
N=1251 \\
\text { (3 sections) }\end{array}$ & $\begin{array}{c}78 \% \\
N=454 \\
\text { (2 sections) }\end{array}$ & $\begin{array}{c}91 \% \\
N=210 \\
\text { (4 sections) }\end{array}$ \\
\hline & $V_{1}+V_{2}$ & & & $\begin{array}{c}81 \% \\
N=90 \\
\text { (3 sections) }\end{array}$ & $\begin{array}{c}94 \% \\
N=18 \\
\text { (2 sections) }\end{array}$ & $\begin{array}{l}93 \% \\
\quad N=58 \\
\text { (4 sections) }\end{array}$ \\
\hline \multirow[t]{3}{*}{ BKO12 } & $V 1$ & & $\begin{array}{c}85 \% \\
N=278 \\
\text { (1 section) }\end{array}$ & $\begin{array}{c}78 \% \\
N=1481 \\
\text { (8 sections) }\end{array}$ & $\begin{array}{c}91 \% \\
N=499 \\
\text { (4 sections) }\end{array}$ & $\begin{array}{c}91 \% \\
N=399 \\
\text { (3 sections) }\end{array}$ \\
\hline & $\mathrm{V} 2$ & & & $\begin{array}{c}78 \% \\
N=3176 \\
\text { (8 sections) }\end{array}$ & $\begin{array}{c}98 \% \\
N=706 \\
\text { (4 sections) }\end{array}$ & $\begin{array}{c}97 \% \\
N=394 \\
\text { (3 sections) }\end{array}$ \\
\hline & $v_{1}+v_{2}$ & & & $\begin{array}{c}96 \% \\
N=281 \\
\text { (8 sections) }\end{array}$ & $\begin{array}{c}98 \% \\
N=104 \\
\text { (4 sections) }\end{array}$ & $\begin{array}{c}91 \% \\
N=178 \\
\text { (3 sections) }\end{array}$ \\
\hline BKO6 & $V_{1}$ & & $\begin{array}{c}78 \% \\
N=173 \\
(1 \text { section) }\end{array}$ & & & \\
\hline
\end{tabular}

${ }^{a}$ Ant. Bank LS, anterior bank of the lunate sulcus; PLG, prelunate gyrus; STS, superior temporal sulcus.

collateral to V2. In other words, one in every three to six neurons in the anterior bank of the lunate sulcus and prelunate gyrus which projects to V1 also sends a projection to V2. Much lower percentages of neurons in the anterior bank of the lunate sulcus and the prelunate gyrus ( 4 to $13 \%$ ) which project to V2 also have collaterals innervating $\vee 1$. This is due to the strong nonbifurcating input to $V 2$ of these cortical regions. Where the input to both areas is similar in strength, as in the superior temporal sulcus, the three different methods of expressing the percentage of double-labeled neurons give similar results.

Quantitative estimation of the proportion of double-labeled neurons in infragranular layers shows that there is a tendency for these neurons to be more numerous in deep layers (Table $\mathrm{V}$ ). The proportion of single- and double-labeled neurons and their laminar distributions are shown in graphic form in Figure 11, which summarizes the figures given in Tables II and III.

Distribution of labeled cells in subcortical structures. Labeled neurons were found in the LGN after injections in V1 or V2. Following injection in V1, labeled cells were located principally in the laminae where they were very densely packed (Fig. 1). V2 labeled neurons, in contrast, were rare, more scattered, and concentrated in the interlaminar zones and S layers (Bullier and Kennedy, 1983).

Both populations of neurons were found in several extrageniculate subcortical structures and, where the density of labeling has permitted, we have quantified the strength of the input to both areas. The results of this quantification are presented in Table VI.

In all animals injected, the pattern of labeling in the lateral pulvinar had a characteristic $V$ shape as shown in Figures 12 to 14. The apex of the $V$ was always found lying on a line describing an arc running parallel to the limits of the lateral and inferior pulvinar and corresponding to a transition line between two regions on myelinstained sections (Figs. 13 and 14). As shown by Bender (1981) and Ungerleider et al. (1983), this transition line separates two represen- tations of the contralateral visual hemifield in the pulvinar. One is contained entirely within the lateral pulvinar $(P L)$ and the other representation (PL-PI) extends from the lateral to the inferior pulvinar. The outer arm of the $V$ in Figures 12 to 14 is entirely contained within the PL division, whereas the PL-PI division contains the inner arm of the $V$ as well as labeled cells in PI. The proportions of neurons projecting to $\mathrm{V} 1$ or $\mathrm{V} 2$ from either representation ( $\mathrm{PL}$ and $\mathrm{PL} \cdot \mathrm{PI}$ ) were computed and are presented in Table $\mathrm{VI}$ and Figure 16. It is clear that the pulvinar input is stronger to $V 2$ than to $V 1$, especially from the PL subdivision where the V1 projection appears to be very wcak compared to the V2 projection (Figs. 12 to 14 , Table VI).

A good retinotopic correspondence was important for obtaining overlap in the populations of labeled neurons in the pulvinar. This is particularly true for the inferior pulvinar as shown in Figure 14. This figure shows the pattern of pulvinar labeling in BKO5 where the retinotopic correspondence between injections was poor. In this case there was practically no overlap in the inferior pulvinar between the population of cells projecting to $\mathrm{V} 1$ and those projecting to V2.

The pattern of labeling in the claustrum is presented in Figure 15. Neurons were always found in the deeper part of the claustrum and the overlap between the populations was generally substantial. The precision of the retinotopic correspondence between the injection sites did not appear to be such a critical factor as for the pulvinar, since overlap remained substantial in BKO5 where the retinotopic correspondence was poor.

Labeling was also observed in a number of other subcortical structures including the intralaminar nuclei, the nucleus basalis of Meynert, and the amygdala. The small numbers of labeled neurons in one or both populations did not allow quantification to be made of the strength of these afferents to $V_{1}$ and $V_{2}$.

Bifurcating axons in subcortical afferents to $V 1$ and V2. In all of the structures mentioned in the preceding section, double-labeled neurons were observed in the region of overlap between the two 
populations of labeled neurons. This is apparent in Figures 12 to 15 for the pulvinar and the claustrum. Double-labeled cells were also observed in the nucleus basalis of Meynert and the amygdala.

The proportion of double-labeled neurons was of the order of 5 to $19 \%$ when expressed with respect to the total number of labeled cells in the region of overlap between the two populations. This is shown in Table VI and graphically in Figure 16. The values are considerably higher when the percentages are expressed with respect to the number of afferents to one cortical area (Table VII). Thus, up to $43 \%$ of the neurons in the claustrum which project to $\mathrm{V} 1$ also send a collateral to $\mathrm{V} 2$. Similarly, approximately one neuron in five which projects from the pulvinar or the claustrum to $V_{2}$ also sends a collateral to $\mathrm{V} 1$.

\section{Discussion}

The simultaneous use of two retrograde tracers presents major advantages. First, it is possible to detect neurons which send bifurcating connections to both injected regions. Second, one can compare the relative strength and spatial distribution of both populations of labeled neurons in a given structure. Before proceeding to discuss these principal aspects of the results, let us try to estimate their validity from a technical point of view.

The interpretation that double-labeled neurons have bifurcating axonal projections requires that the two dyes cannot be captured by a single neuron by any means other than retrograde transport along two axonal collaterals. We have already dismissed the possibility of spurious labeling by transport in the vascular system (Bullier et al. 1984a). Similarly, we have controlled for possible uptake subsequent to leaking into extracellular space following retrograde
BKO 6

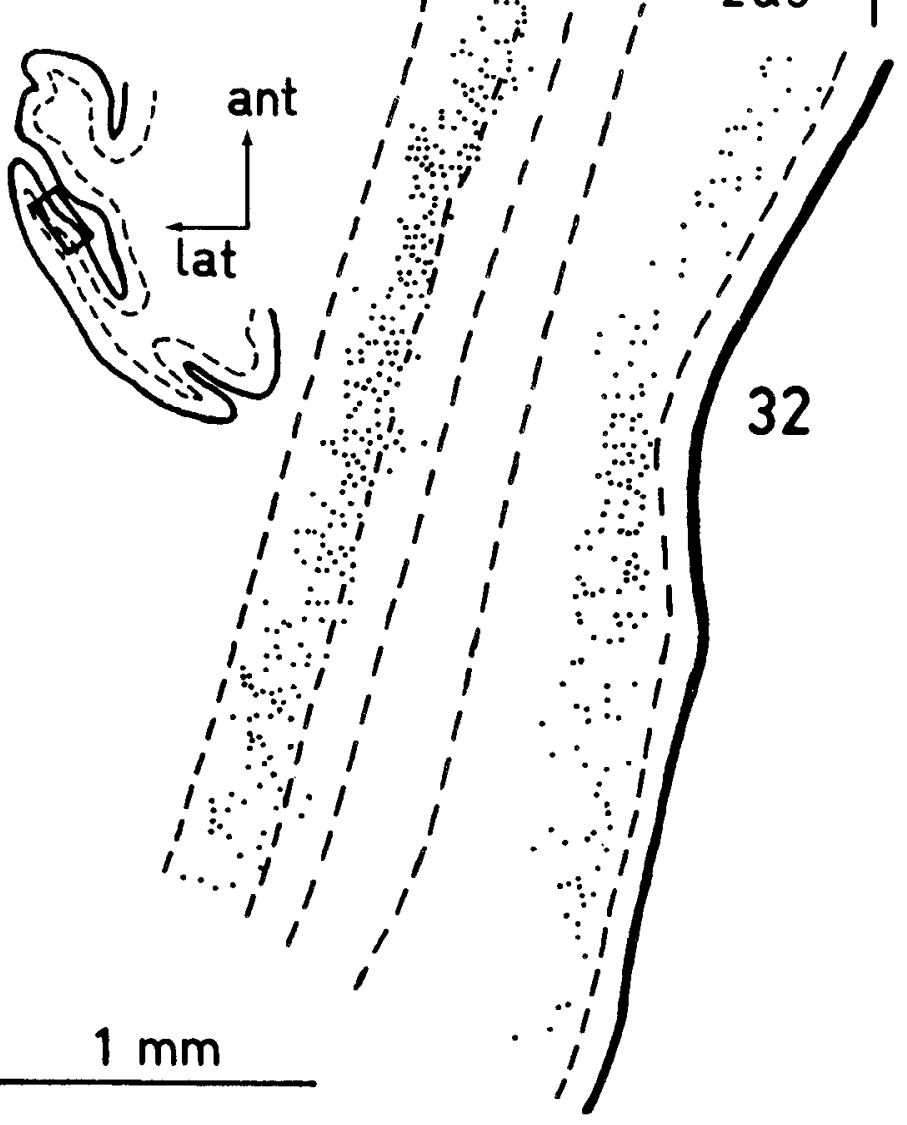

Figure 7. Laminar distribution of labeled cells in V2 after injection in V1. Same conventions as in Figure 6.

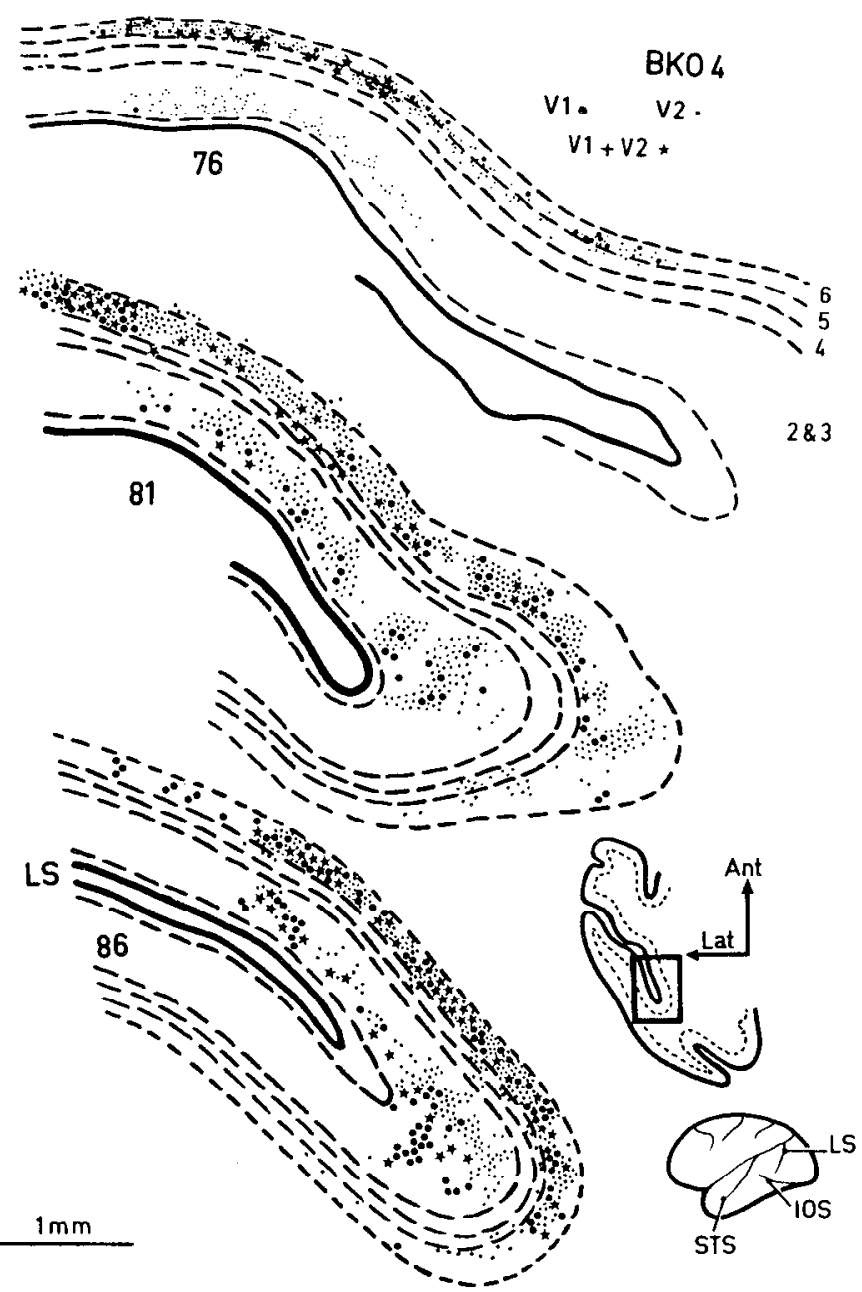

Figure 8. High power view of labeled cells in the anterior bank of the lunate sulcus after the injections shown in Figure 2. I lorizontal sections. Large dots, neurons back-filled with the fluorescent dye injected in V1; small dots, neurons back-filled with the fluorescent dye injected in V2; stars, double-labeled neurons. Other conventions are as in Figure 2.

or anterograde transport of the dyes. Since both DY and FB are found in close proximity in a number of regions of labeled cells, one could argue that some of the double-labeling is artificially created by dyes leaking out of some cells and subsequently being picked up by others. This appears very unlikely, as on numerous occasions we have observed very high densities of single-labeled cortical neurons with no or very few double-labeled cells in the vicinity (see labeling in upper layers in section 81 of Fig. 8; see also Fig. 1 in Bullier et al., 1984b).

It is crucial that the dyes be only captured by axonal terminals in the immediate vicinity of the injection site, and it is therefore imperative to be able to relate the uptake zone of each dye with respect to its injection site. This is possible by examining the pattern of retrograde labeling following adjacent injections within a single area. In both cat and monkey, the DY and FB columns of cells in the LGN are distinct if the injections in area 17 are separated by as little as 2 $\mathrm{mm}$ (this report and Bullier et al., 1984a). The diameter of the uptake region is given by this minimum distance between injection sites minus the average lateral extent of the terminal arbors of geniculocortical afferents. These arbors span several hundred micrometers (Blasdel and Lund 1983; Humphrey et al. 1985) and, therefore, the uptake zone is of the order of $1.5 \mathrm{~mm}$. This corresponds approximately to the extent of the zone of dense extracellular coloring surrounding the needle track. When these regions of dense coloring were restricted to the gray matter of $\mathrm{V} 1$ and $\mathrm{V} 2$, we could conclude that the uptake was restricted to these cortical areas. In these cases 
an additional control was provided by observations of the LGN Neurons labeled by the dye injected in V2 were more scattered and mostly located in the interlaminar zones and $S$ layers (Bullier and Kennedy, 1983), whereas the cells labeled by the dye injected in V1 were found in dense columns within the main laminae (Fig. 1). The sparsity of labeling with the V2 dye indicated that this label had not

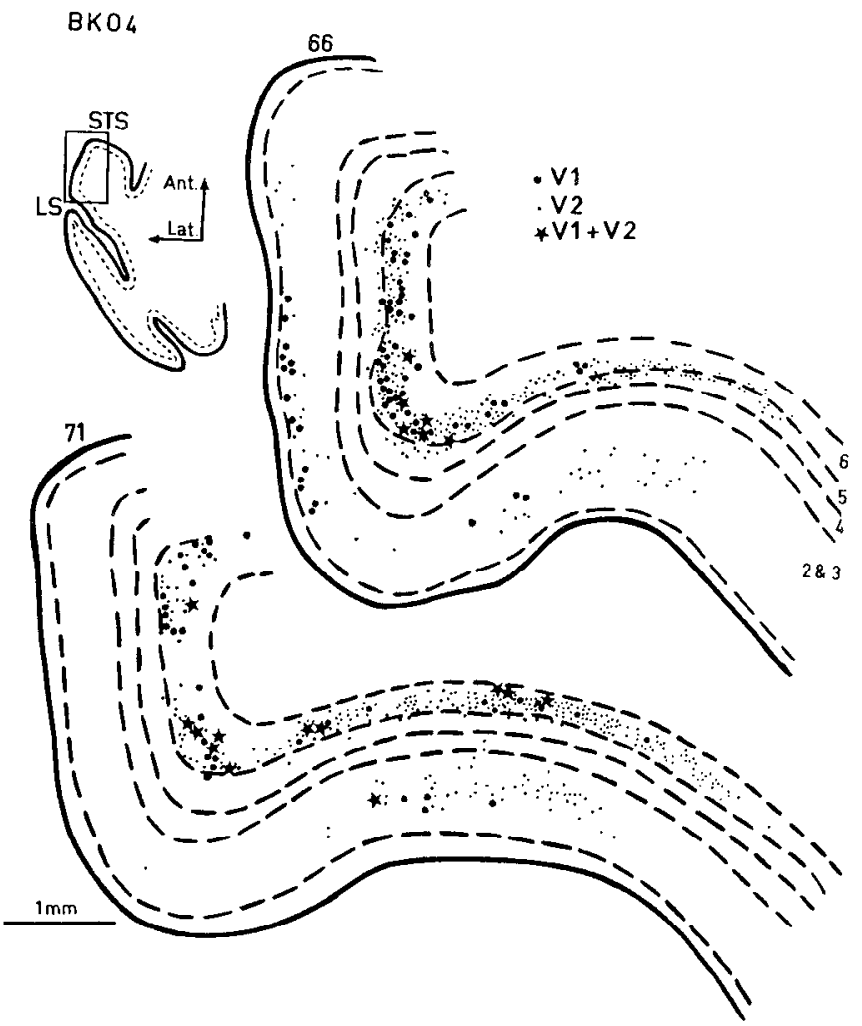

Figure 9. High power view of labeled cells in the prelunate gyrus after the injections shown in Figure 2. I arge dots, neurons back-filled with fluorescent dye injected in $V_{1}$; small dots, neurons back-filled with fluorescent dye injected in V2. Stars, double-labeled neurons. Other conventions are as in Figure 2 . invaded V1. Since the V2 injections were made in the posterior bank of the lunate sulcus and did not approach the fundus where the anterior limit of V2 is situated (Van Essen and Zeki, 1978; Gattass et al., 1981), it is highly unlikely that cortical areas other than V2 were concerned by these injections. We controlled for uptake of the dyes by neurons in the anterior bank of the lunate sulcus by
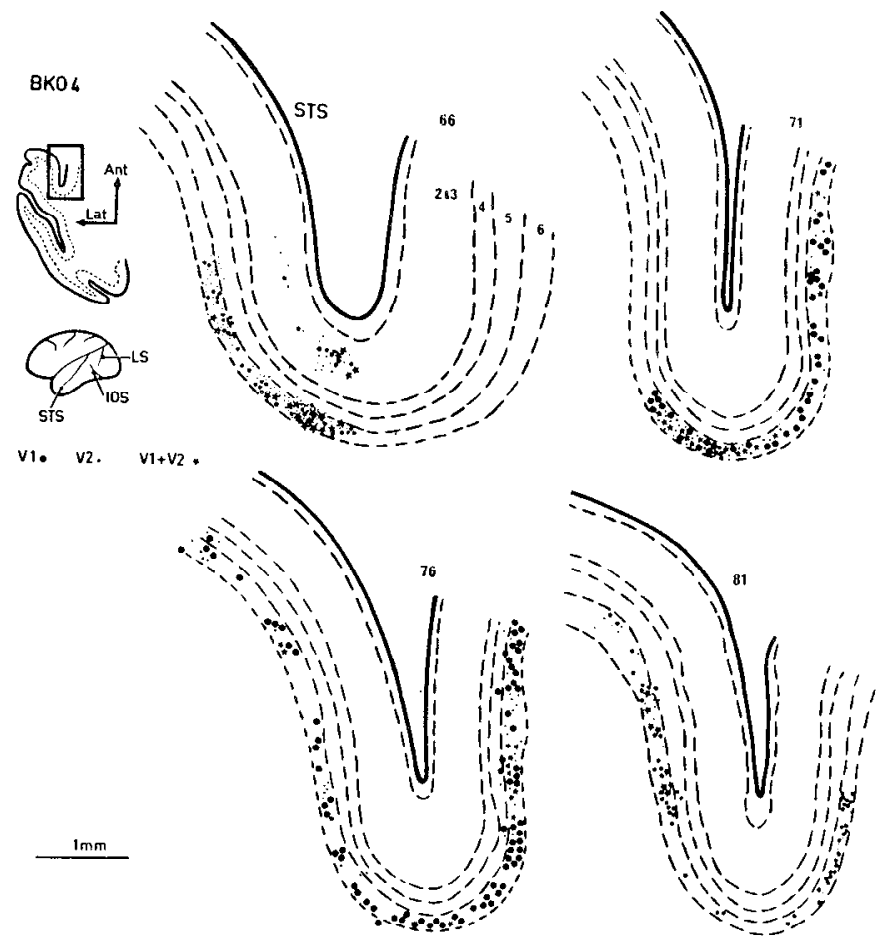

Figure 10. High power view of labeled cells in the fundus and posterior bank of the superior temporal sulcus after injections shown in Figure 2. Large dots, neurons back-filled with fluorescent dye injected in $\mathrm{V} 1$; small dots, neurons back-filled with fluorescent dye injected in V2; stars, double-labeled neurons. Other conventions are as in Figure 2.

TABLE IV

Different methods of expressing the proportions of cortical neurons sending a bifurcating axon to $\mathrm{V} 1$ and $\mathrm{V} 2$, with respect to the total population of labeled neurons (total), with respect to the total number of neurons sending a connection to V1 (V1), and with respect to the total number of neurons projecting to V2 (V2)

\begin{tabular}{clll}
\hline Case & \multicolumn{1}{c}{ Ant. Bank LS } & \multicolumn{1}{c}{ PLG } & \multicolumn{1}{c}{ STS } \\
\hline BKO4 & total: $6 \%(N=1637)$ & total: $3 \%(N=568)$ & total: $12 \%(N=484)$ \\
& V1: $32 \%(N=297)$ & V1: $16 \%(N=114)$ & V1: $21 \%(N=274)$ \\
& V2: $6.5 \%(N=1434)$ & V2: $4 \%(N=472)$ & V2: $22 \%(N=268)$ \\
BKO12 & total: $6 \%(N=4938)$ & total: $8 \%(N=1309)$ & total: $18 \%(N=971)$ \\
& V1: $16 \%(N=1762)$ & $V 1: 17 \%(N=603)$ & $V 1: 31 \%(N=577)$ \\
& V2: $8 \%(N=3457)$ & V2: $13 \%(N=810)$ & $V 2: 31 \%(N=572)$ \\
\hline
\end{tabular}

${ }^{a}$ Ant. Bank LS, anterior bank of the lunate sulcus; PLG, prelunate gyrus; STS, superior temporal sulcus.

TABLE V

Proportions of double-labeled cells in infra- and supragranular layers with respect to the total numbers of labeled cells in these layers in the region of overlap

\begin{tabular}{clll}
\hline Case & \multicolumn{1}{c}{ Ant. Bank LS } & \multicolumn{1}{c}{ PLG } & STS \\
\hline BKO4 & & & $13 \%(N=31), 4$ sections \\
$\quad$ supragranular & $4 \%(N=441), 3$ sections & $1 \%(N=123), 2$ sections & $12 \%(N=453), 4$ sections \\
$\quad$ infragranular & $6 \%(N=1196), 3$ sections & $4 \%(N=445), 2$ sections & \\
BKO12 & & & $2 \%(N=46), 3$ sections \\
supragranular & $1 \%(N=1024), 8$ sections & $3 \%(N=62), 4$ sections & $19 \%(N=925), 3$ sections \\
infragranular & $7 \%(N=3914), 8$ sections & $8 \%(N=1247), 4$ sections & $19 \%(N)$.
\end{tabular}

${ }^{a}$ Ant. Bank LS, anterior bank of the lunate sulcus; PLG, preiunate gyrus; STS, superior temporal sulcus. 


\section{BKO4 BKO12}
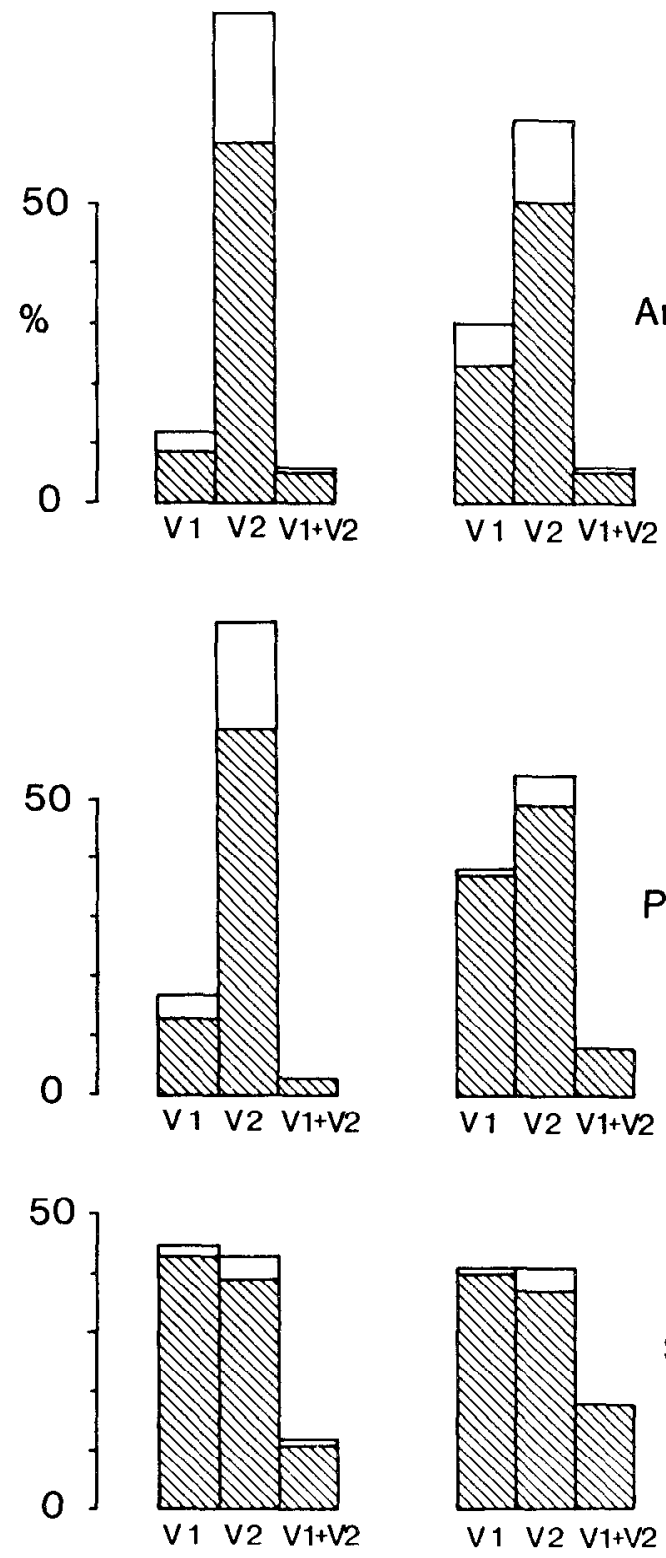

\section{Superior Temporal Sulcus}

Figure 11. Histograms of the percentages of cells in various prestriate regions projecting to $V_{1}, V_{2}$, and $V_{1}+V_{2}$ (double-labeled cells). Shading shows the proportion of cells in cortical layers 5 and 6 . LS, lunate sulcus.

examining the sulcus for fluorescent dyes and by observing the laminar position of labeled cells in the anterior bank of the lunate sulcus. Leaking of the dyes into the sulcus would give rise to local labeling in the most superficial cortical layers of the anterior bank. As we observed mostly infragranular labeling, such a likelihood can be discounted.

The conclusion that the $\mathrm{V} 1$ injections were restricted to this area rests heavily on the location in the gray matter of $V 1$ of the estimated maximal uptake zone and the pattern of labeling in the LGN. In three cases BKO4, BKO5, and BKO12, labeled cells were not found right up to the medial edge of the posterior pole of the LGN, which would have been the case if dye had been picked up in the vicinity of the V1-V2 border (Malpeli and Baker, 1975; Connolly and Van Essen, 1984). It is also highly unlikely that the dye injected in V1 leaked into V2 across the white matter separating the operculum from the posterior bank of the lunate sulcus, as this would result in a dense labeling of neurons in the deeper part of layer 6 , which was never observed (Fig. 7).

Bifurcation of axonal input to $\mathrm{V} 1$ and $\mathrm{V} 2$. It may well be that the proportion of double-labeled neurons is underestimated because of the difficulties associated with their detection. First, if an FB-positive cell is not sectioned through the nucleus it is impossible to classify it unambiguously as an FB-positive single-labeled neuron. Ascertaining whether each FB-positive cell was sectioned through the nucleus would greatly lengthen the plotting procedure and therefore limit the number of neurons sampled. Second, observation of these dyes with UV light leads to a fading of their fluorescence due to oxidation (Spatz and Grabig, 1983). Fading can be more pronounced for either dye, depending on the strength of label, and particularly so in double-labeled cells. For these reasons we submit that in this report we underestimate the proportions of double-labeled neurons.

A major finding of the present report is the ubiquity of doublelabeled neurons. All structures which project to both areas contained some double-labeled neurons when the two populations of singlelabeled neurons were found in a sufficiently high density. Doublelabeled neurons were not found uniformly throughout the afferent structures but were concentrated in those regions where the two populations of FB- and DY-positive neurons were coextensive. Assuming that connections in the visual system link regions which represent a common portion of the visual field, the zone of overlap in afterent structures of the two populations of back-tilled cells delimits a region representing visual space which is coded in part of the cortex concerned by each injection. Increasing the correspondence between injection sites results in an increase in the extent of the overlap. However injections in cortical regions showing poor retinotopical correspondence still resulted in a high degree of overlap at the cortical but not the subcortical level (Figs. 3, 5, and 14). This means that paired injections which give rise to thalamic labeling representing distinct regions of the visual field can, at the cortical level, give rise to labeling of common territories. The fact that the topography of the projection of the thalamus onto the cortex is stricter than that of corticocortical projections reflects the greater degree of divergence in cortical connectivity which could be an important feature underlying cortical function (Barlow, 1981).

Regions of overlap of the two populations of single-labeled neurons in prestriate cortex and the concomitance of double-labeled neurons were not limited to injections within separate areas. Adjacent injections in $V 1$ separated by 2 to $4 \mathrm{~mm}$ which gave rise to separate columns of DY and FB cells in the LGN (see Fig. 1) also resulted in an overlap in the prestriate cortex of the two cell populations which contained a small proportion of double-labeled neurons (D. J. Perkel, $J$. Bullier, and $H$. Kennedy, unpublished result).

The finding that double-labeled neurons are restricted to the zone of overlap reflects the high level of precision in the bifurcation of axon collaterals. Since this is true in cortical connections despite the high degree of divergence, the presence or absence of axonal branching is not dictated by the relative location of the visual field represented in the target zones, and collaterals can project to retinotopically noncorresponding points on the cortex. The finding that double-labeled neurons are restricted to the overlap zone indicates that the laws governing the trajectory of collaterals are similar to those governing precision of the overall projection. This is not a trivial point, eliminating as it does the possibility that bifurcation results in an erosion of topographical order in corticocortical connections.

Since the dye injections involved cortical regions representing large portions of the visual field, the cortical zones of overlap between the two populations of labeled neurons can be considered heterogeneous, with a central core linked to retinotopically corresponding parts of each injection flanked by overlap zones linked to noncorresponding regions. This raises the question of whether the central core contains more double-labeled neurons than does the lateral zones. Although we cannot directly answer this question, the fact that the proportion of double-labeled neurons was not substan- 
TABLE VI

Percentages of neurons in subcortical structures projecting to $V_{1}, V_{2}$, or V1 and V2 via a branching axon

\begin{tabular}{|c|c|c|c|}
\hline Case & PL-PI & $\Gamma \mathrm{L}$ & $\mathrm{Cl}^{a}$ \\
\hline $\mathrm{BKO} 4$ & $\begin{array}{l}V 1: 35 \% \\
\text { V2: } 54 \% \\
V 1+V 2: 11 \% \\
N=223 \text { (9 sections) }\end{array}$ & $\begin{array}{l}V 1: 20 \% \\
V 2: 68 \% \\
V 1+V 2: 12 \% \\
N=50 \text { ( } 3 \text { sections) }\end{array}$ & $\begin{array}{l}\text { V1: } 26 \% \\
\text { V2: } 55 \% \\
\text { V1 + V2: } 19 \% \\
N=234 \text { (7 sections) }\end{array}$ \\
\hline BKO12 & $\begin{array}{l}\text { V1: } 31 \% \\
\text { V2: } 60 \% \\
\text { V1 + V2: } 9 \% \\
N=582 \text { (8 sections) }\end{array}$ & $\begin{array}{l}V 1: 7 \% \\
\text { V2: } 88 \% \\
\text { V1 + V2: } 5 \% \\
N=172 \text { ( } 5 \text { sections) }\end{array}$ & $\begin{array}{l}\text { V1: } 53 \% \\
\text { V2: } 36 \% \\
\text { V1 }+ \text { V2: } 11 \% \\
N=227 \text { (4 sections) }\end{array}$ \\
\hline
\end{tabular}

${ }^{a} \mathrm{Cl}$, claustrum; $\mathrm{PL}$, lateral pulvinar; $\mathrm{PI}$, inferior pulvinar.
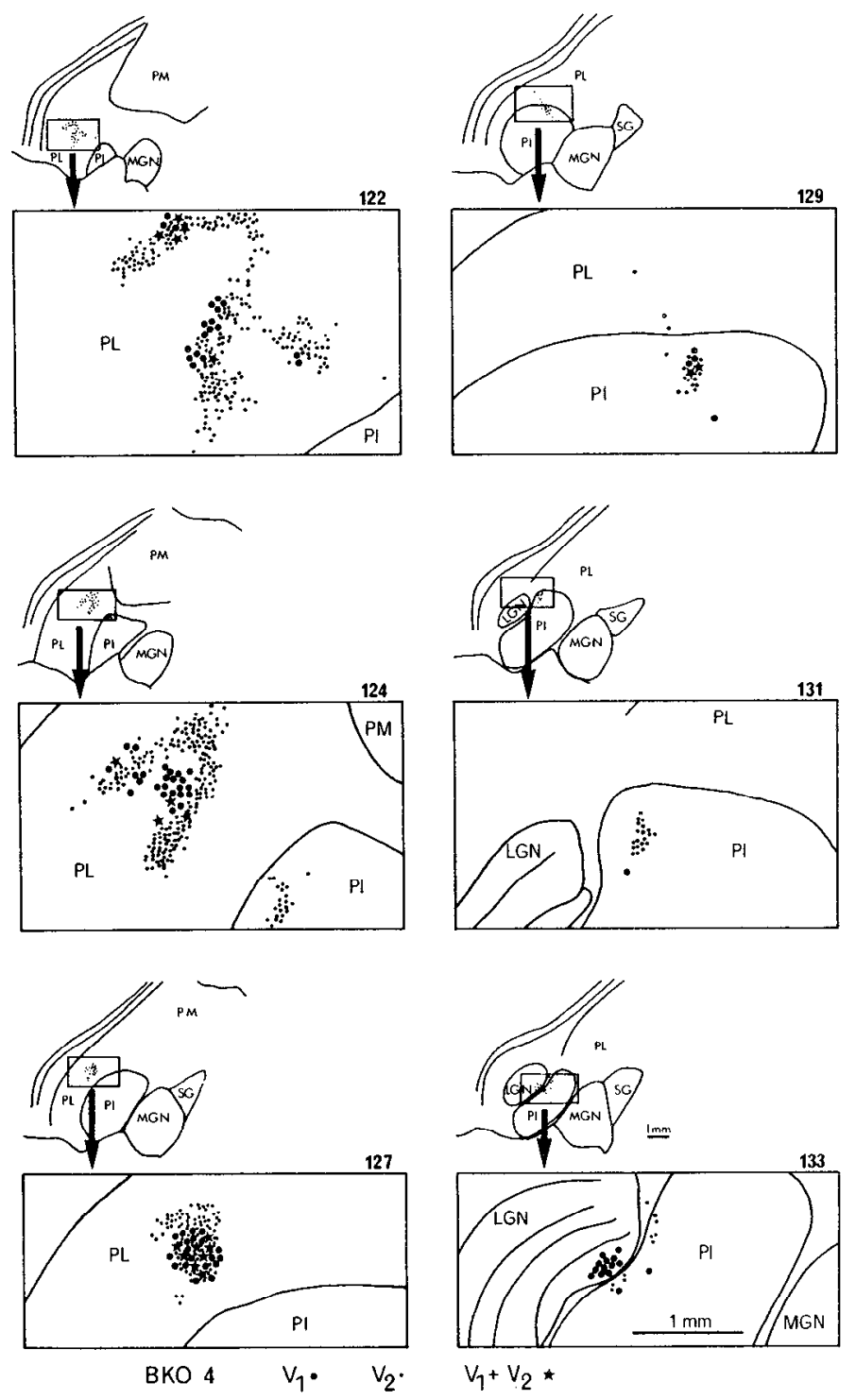

$v_{1}+v_{2} \star$

Figure 12. Distribution of labeled cells in the pulvinar after the injections shown in Figure 2. Frontal sections. Section numbers increase from caudal to rostral. Each rectangle represents a magnified view of the rectangle outlined in the sketch above. Small dots, neurons labeled by the V2 injection; large dots, neurons labeled by the $V 1$ injections; stars, double-labeled neurons. $P L$, lateral pulvinar; $P$, inferior pulvinar; $P M$, medial pulvinar; $M G N$, medial geniculate nucleus; $S G$, suprageniculate nucleus.

tially smaller in BKO5 than in BKO4 and BKO12 suggests that the amount of bifurcation might not be dictated by retinotopic correspondence.

There are other theoretical considerations which must also be taken into account. Expressing the percentage of double-labeled neurons with respect to the total number of single-labeled neurons projecting to either area or, alternatively, with respect to each individual population leads, as we have seen, to very different sets of figures. Both methods of quantification are equally valid but nevertheless constitute different ways of looking at cortical connectivity. Calculating the percentage of double-labeled neurons as a percentage of the total population amounts to an expression of the incidence of bifurcation in the output of the area of origin, whereas expressing the percentage with respect to a single population expresses the incidence of bifurcation of the input to one of the target areas. Differences in the number of neurons projecting to $V 1$ and $V 2$ will have an influence on the relative strength of branched input calculated by the second method. When the input to one area is much stronger, then any number of double-labeled cells will indicate a higher incidence of bifurcation in the minority population. For example, the superior temporal sulcus contains equal numbers of neurons projecting to $V 1$ and $V 2$, and expressing the percentage of double-labeled cells in terms of the input to either area leads to estimates which remain fairly similar (Table IV). Elsewhere the proportion of input to $V_{2}$ is much stronger than that to $V_{1}$ and, hence, the percentage of branched input to $V 1$ is much higher than that to V2.

Spatial distribution and relative strength of input to $V_{1}$ and $V_{2}$. Those structures which project to both $V_{1}$ and $V 2$ may have separate subregions which project separately to each area or, alternatively, neurons projecting to either area may be intermingled. To be able to distinguish between these two possibilities it is necessary to compare spatial distributions of the two populations of back-filled cells following injections concerning cortical regions in V1 and V2 representing the same part of the visual field, which was the case in $\mathrm{BKO} 4$ and $\mathrm{BKO} 12$. This ensures that differences in distribution of the afferents to the two arcas do not simply roflect differences in topography.

The overlap between the populations of labeled cells was, however, never total, especially in subcortical structures. This presumably stems from the fact that, in all injections, only part of each injection concerned retinotopically corresponding regions. In this region of overlap, we have attempted to evaluate the relative strengths of the connections to the two injected areas.

A comparison of the number of labeled neurons projecting to each area after small identical injections would provide an ideal indication of the strength of input. Computation of strength of input following such paired injections is not without some theoretical difficulties, however. As V1 has a much higher magnification factor than $V 2$, injection, say, of $1 \mathrm{~mm}^{3}$ in each area would lead to a larger spatial extent in a given afferent cortical area of neurons labeled with the dye injected in V2. One would then be faced with the choice of whether to compare the total numbers of back-labeled neurons containing each dye or to estimate the proportions of a fixed volume of the afferent structures. The latter method amounts to comparing the numbers of neurons afferent to a volume of cortex in V1 and V2 representing an identical region of visual space and is, therefore, independent of the differences of magnification factor. This can be considered as a fixed retinal space measure of the strength of input as opposed to a fixed cortical volume measure as provided by the 
total neuron counts of each population. These two measures constitute different paradigms and tell us different things about cortical connectivity. If we could make small identical injections in each area we could make both measures. In practice, however, it would be almost impossible to ensure a perfect similarity of two injections which would entail, for example, an inaccessible degree of control of the uptake zone and its disposition with respect to the afferent terminals. One way of overcoming this problem is to estimate the numbers of afferent neurons to a restricted but equivalent part of each injection. This is provided by the overlap zone, which delimits an afferent cortical volume which is retinotopically common to part of each injection in V1 and V2. Estimating the strength of input within the overlap zone also does away with differences in numbers of back-filled cells due to the size of the injection. Since the spatial densities show very broad and rather flat profiles, the estimates are not critically dependent on the relative positions of the density peaks of the two distributions.
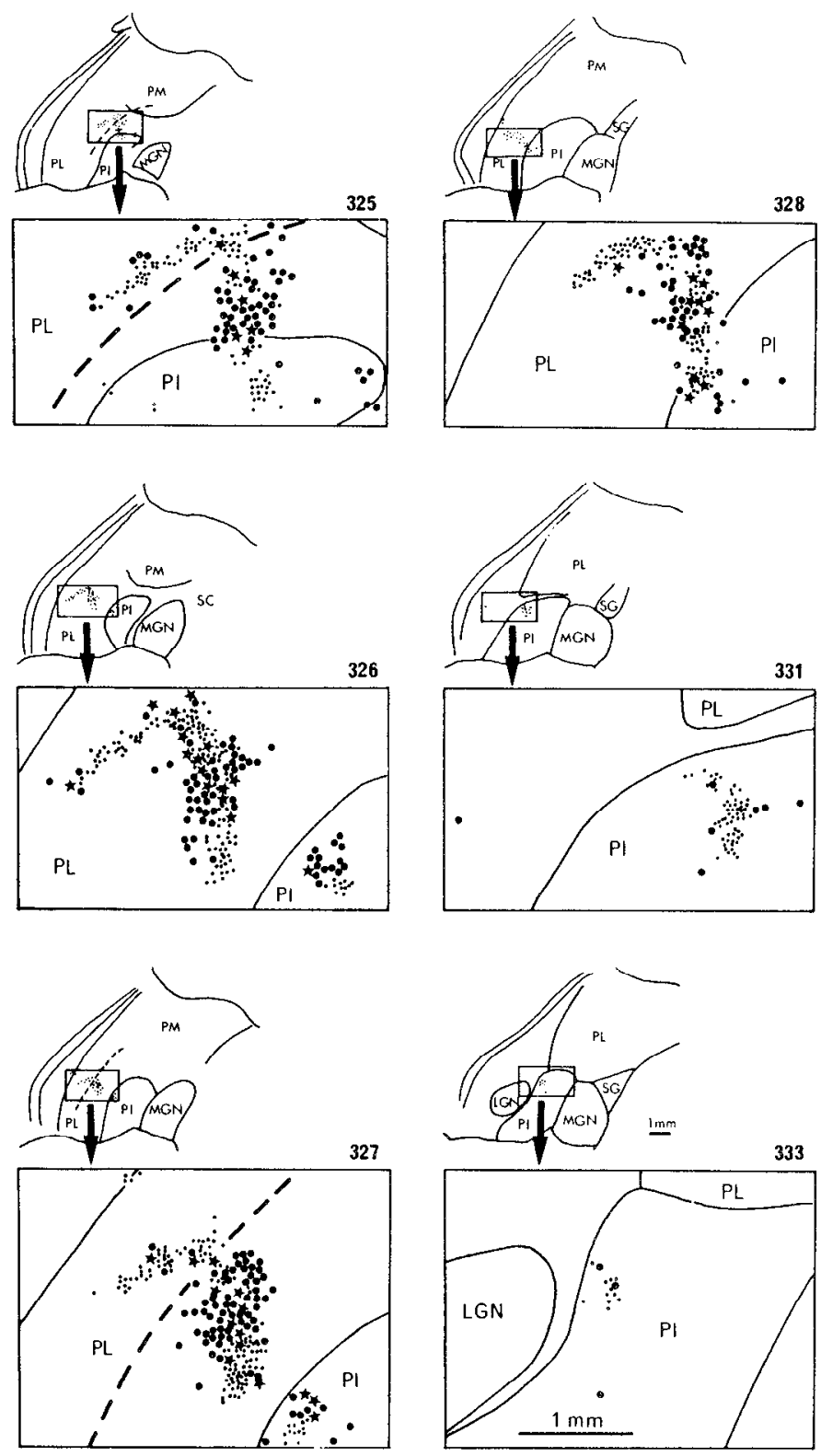

BKO 12

$V_{1} \cdot V_{2}$.

$V_{1}+V_{2} \star$

Figure 13. Distribution of labeled cells in the pulvinar after injections in $\mathrm{V} 1$ and V2 (case BKO12; injection sites not shown). Conventions are as in Figure 12. The dashed line in sections 325 and 327 represents the transition line seen in myelin sections (Bender, 1981).
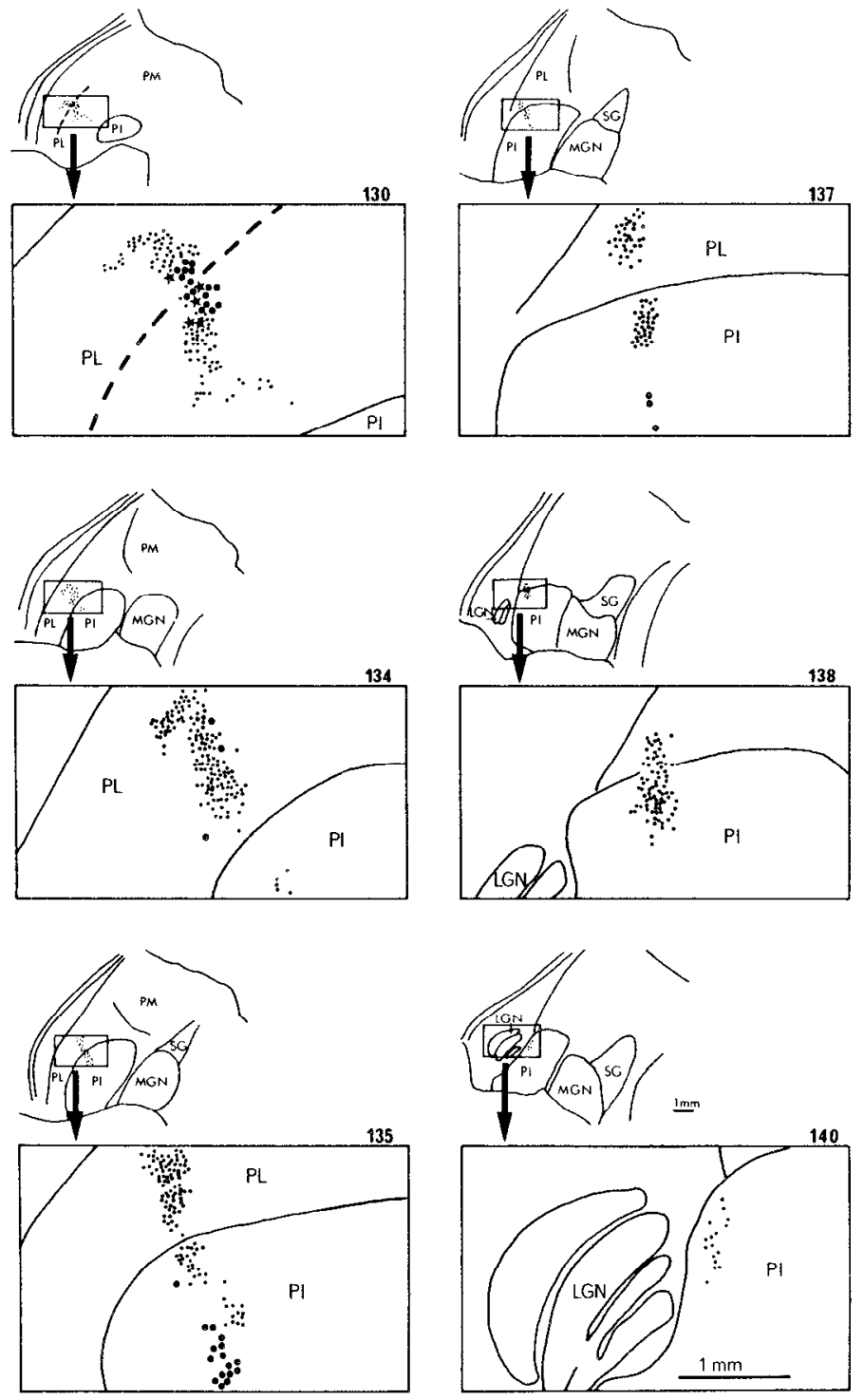

BKO $5 \quad V_{1} \cdot \quad V_{2} \cdot V_{1}+V_{2} *$

Figure 14. Distribution of labeled cells in the pulvinar after injections in $\mathrm{V} 1$ and V2 shown in Figure 3. Same conventions as in Figures 11 to 13.

Our choice of the overlap zone and, hence, of a fixed retinal space measure of input strength has certain advantages, notably when it comes to considering the relative functional positions of the cortical areas within the visual system. Theoretically, if one wanted to compare the input of, say, V3 to V2 and V1, one would want to count the total number of neurons in V3 projecting to each area. This would entail filling the whole of $V_{1}$ and $V_{2}$ with retrograde markers. This clearly is impossible. By using a fixed retinal space measure one is making an estimate of the relative contribution of V3 neurons to the visual processing of a similar number of visual degrees in $\mathrm{V} 1$ and $\mathrm{V} 2$.

The distribution of retrogradely labeled cells in extrastriate cortex revealed extensive regions of overlap between the populations. This means that there is no cortical region projecting to $\mathrm{V} 1$ and not to $\mathrm{V} 2$ and vice versa. Overlap of the afferent cortical populations was still present even in the case of BKO5, where the retinotopic correspondence was poor, suggesting, as discussed above, that there is a larger amount of convergence and divergence in corticocortical connections than in the subcortical afferents. Comparing the strength of input from cortical regions to $V 1$ and $V 2$, it is apparent that the superior ternporal sulcus sends a comparable projection to 


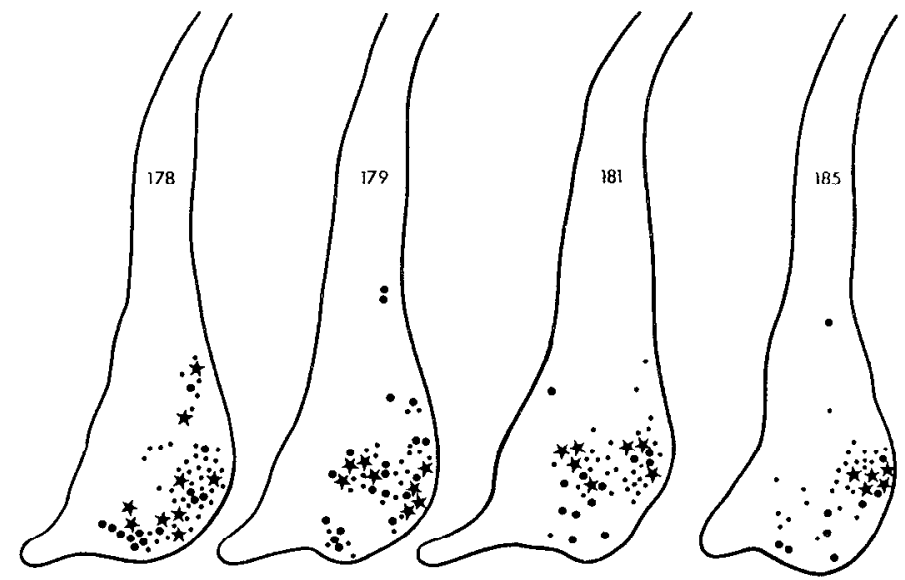

$\mathrm{BKO} 4 v_{1} \cdot v_{2} \cdot v_{1}+v_{2} \star \quad \frac{\min m}{2}$

Figure 15. Labeled cells in the claustrum following injections in $V_{1}$ and V2. Small dots, cells labeled with dye injected in V2; large dots, cells labeled with dye injected in V1; stars, double-labeled cells. Frontal sections. Section numbers increase from caudal to rostral.

$\mathrm{V} 1$ and to $\mathrm{V} 2$, whereas the other regions of extrastriate cortex project more heavily to $V 2$ than to $V 1$ (see the following section).

Neurons labeled by injections in $V_{1}$ and $V_{2}$ were also found in several subcortical structures including the LGN, the lateral and inferior pulvinar, the intralaminar nuclei, the nucleus basalis of Meynert, the amygdaloid nuclei and the claustrum. This confirms, at least for the projections to $\mathrm{V} 1$, the results reported in several publications (Ogren and Hendrickson, 1976; Trojanowski and Jacobson, 1977; Riche and Lanoir, 1978; Rezak and Benevento, 1979; Mizuno et al., 1981; Doty, 1983).

The interesting point concerning the distribution of labeled neurons in subcortical structures is the extensive overlap between the populations of neurons labeled by each injection (BKO4 and BKO12). This demonstrates that there is no subdivision of these subcortical structures according to the projection to V1 and V2 with the exception of the LGN, in which we showed earlier that the V1 projecting neurons predominantly belong to the main laminae of the nucleus, whereas the neurons afferent to $\mathrm{V} 2$ were mostly found in the interlaminar zones and S layers (Bullier and Kennedy, 1983). The overlap between populations of labeled cells in subcortical nuclei also shows that there is no nucleus which projects to $V 1$ and not to $\mathrm{V} 2$ or vice versa. $\mathrm{V} 1$ and $V_{2}$ therefore receive a vast amount of subcortical information coming from the same structures and often from the same neurons.

The spatial distribution of neurons labeled by each dye in subcortical structures consisted of a single group of labeled cells in each nucleus except in the case of the lateral and inferior pulvinar where the distribution was rather more complex (Figs. 12 to 14). The pattern of labeling observed in the present study is consistent with the conclusion of Bender (1981) and Ungerleider et al. (1983), that there are two subdivisions (PL and PL-PI) of the lateral-inferior pulvinar complex. The observation that the PL-PI subdivision has a stronger input to $V 1$ than does the $P L$ suggests that these two subdivisions constitute different functional entities with different sets of connections. This difference in strength of the projection to $\mathrm{V} 1$ was not due to the inclusion of PI in the PL-PI division because the difference in strength of input to $V 1$ and $V 2$ can be seen between the inner and outer divisions of the lateral pulvinar, further emphasizing the validity of the division of this nucleus by mapping studies (Bender, 1981). The cytoarchitectonic heterogeneity of the PL-PI division could be related to the presence of a collicular input restricted to the inferior pulvinar (Benevento and Fallon, 1975; Partiow et al., 1977). Such cytoarchitectonic and connectional heterogeneity between different parts of a single representation of the visual hemifield is relatively common in the thalamus: for example, in the cat, a given region of visual field is represented by a column of cells in the LGN running through layers A, A1, and C. Despite the differences in cytoarchitectony and connectivity between the $C$ layers and layers $A$ and $A 1$, they both code a common region of the visual field. A similar phenomenon exists in the cat lateralposterior (LP) pulvinar complex (Updyke, 1983).

The spatial distribution of labeled neurons in the lateral and inferior pulvinar is, however, more complicated than would be expected in
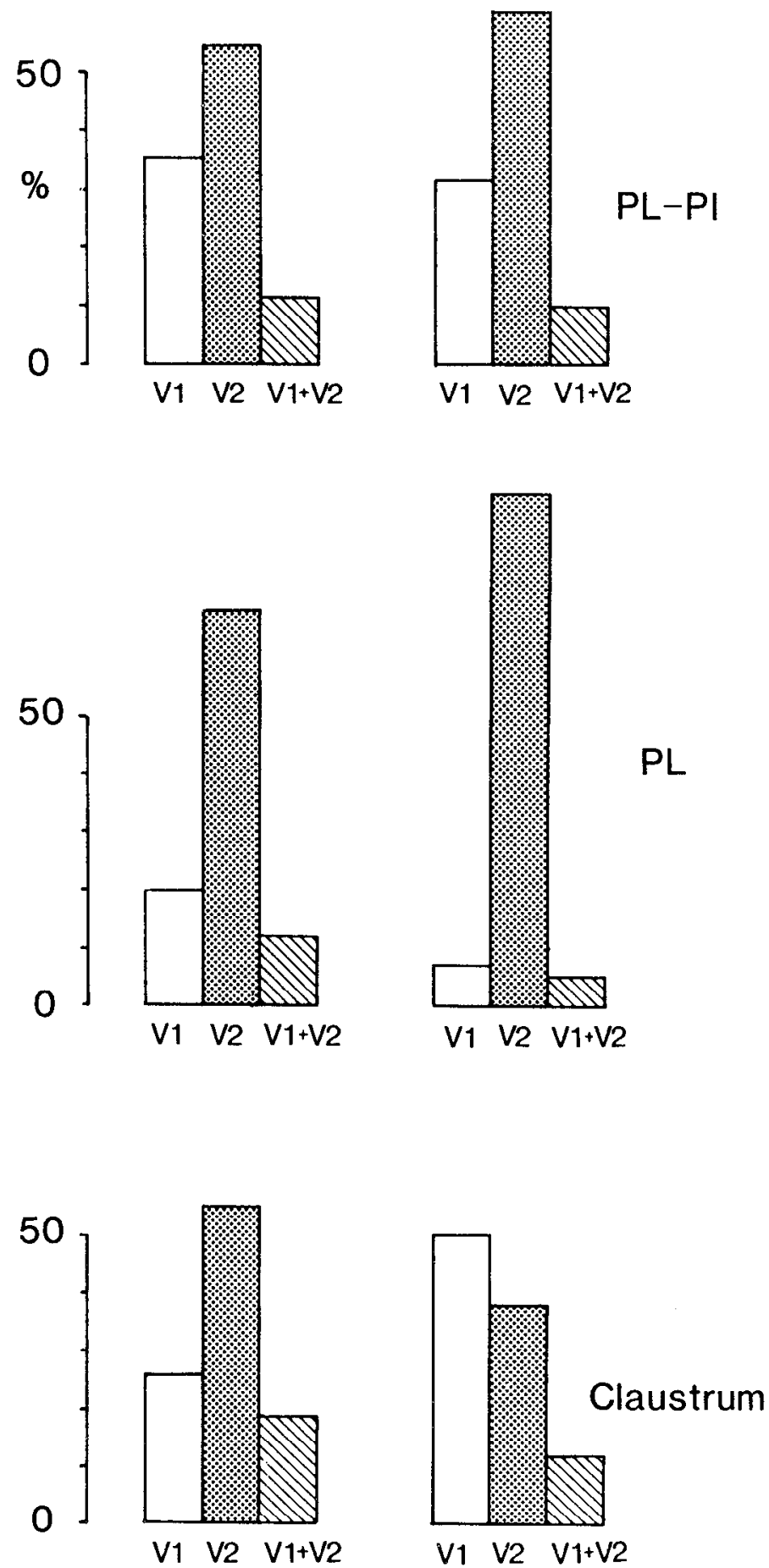

Figure 16. Histograms showing the proportions of cells in subcortical structures projecting to $\mathrm{V} 1, \mathrm{~V} 2$, and $\mathrm{V} 1+\mathrm{V} 2$ (double-labeled cells). $P L$, subdivision of the pulvinar contained in the lateral pulvinar; $P L-P I$, subdivision of the pulvinar extending in the lateral and inferior pulvinar (Bender, 1981). Histogram sets on the left re for $\mathrm{BKO4}$; those on the right are for $\mathrm{BKO} 12$ (as in Fig. 11). 
TABLE VII

Different methods of estimating the percentage of subcortical neurons sending a bifurcating axon to V1 and V2, with respect to the total number of labeled neurons (total), with respect to the total number of neurons projecting to $V 1$ (V1), and with respect to the total number of neurons projecting to V2 (V2)

\begin{tabular}{clll}
\hline Case & \multicolumn{1}{c}{ PL-PI } & \multicolumn{1}{c}{ PL } & $\mathrm{Cl}^{a}$ \\
\hline BKO4 & total: $11 \%(N=223)$ & total: $12 \%(N=50)$ & total: $19 \%(N=234)$ \\
& $V 1: 24 \%(N=103)$ & $V 1: 37 \%(N=16)$ & $V 1: 43 \%(N=106)$ \\
BKO12 & V2: $17 \%(N=145)$ & $V 2: 15 \%(N=40)$ & $V 2: 26 \%(N=174)$ \\
& total: $9 \%(N=582)$ & total: $5 \%(N=171)$ & total: $11 \%(N=227)$ \\
& $V 1: 22 \%(N=230)$ & $V 1: 40 \%(N=20)$ & $V 1: 17 \%(N=147)$ \\
& $V 2: 13 \%(N=403)$ & $V 2: 5 \%(N=160)$ & $V 2: 23 \%(N=107)$ \\
\hline
\end{tabular}

${ }^{a} \mathrm{Cl}$, claustrum; PL, lateral pulvinar; $\mathrm{PI}$, inferior pulvinar.

the case of two single retinotopic representations of the contralateral hemifield. This is especially true in the caudal portion of the pulvinar where three regions of labeled neurons can be identified, two in the lateral pulvinar and one at the border of the inferior and lateral pulvinar (Figs. 12 to 14). This is consistent with the observations of Ungerleider et al. (1983) on the projections of V1 onto the pulvinar and with the results of the mapping experiments of Bender (1981), who noted some unexpected reversals in the progression of receptive fields during penetrations in the caudal part of the inferior and lateral pulvinar. It is therefore possible that there is a third representation of the foveal and parafoveal visual field in the caudal part of the lateral and inferior pulvinar, whereas more peripherai parts of the visual field are only mapped twice in these nuclei.

The results of the present study are comparable to those in subcortical structures after injection in the cat visual areas (Bullier et al., 1984a). In both species, after injections in V1 and V2, there appear to be no subdivisions of different nuclei according to their cortical projection, and neurons projecting to either area are intermingled, some projecting to both areas by a bifurcating axon. The difference in relative strength of the projections to $V_{1}$ and $V_{2}$ in the macaque pulvinar is comparable to the situation observed in the cat LP-pulvinar complex after injection in areas 18 and 19 (Bullier et al., 1984a). There also, we found that one division of this complex (the pulvinar proper) projected more heavily to one area (area 19) than to the other, whereas the projection from another subdivision (LPI) to both areas was more balanced.

Laminar distribution. The laminar location of retrograde labeled cells was found to be dictated by the region of cortex in which they were situated rather than by the target area. The laminar distribution of corticocortical cells was most complex in area $\mathrm{V} 1$, where they were located in layers $2 / 3,4 \mathrm{~B}$, and $5 / 6$. This distribution is reminiscent of the pattern of locally labeled cells found around the injection sites and indicates that corticocortical cells, at least between V1 and V2, have extensive lateral connectivity.

It has long been established that neurons in layers 2 and 3 in $\mathrm{V} 1$ project to V2 (Spatz et al., 1970; Martinez-Millan and Hollander, 1975; Rockland and Pandya, 1979). Lund et al. (1981) reported retrograde labeled cells in layers $2,3,4 A$, and $4 B$ in $V 1$ following horseradish peroxidase (HRP) injections in V2 as did Rockland and Pandya (1979). These authors did not show a graphical representation of their findings and, thus, it is difficult to make a direct comparison between their results and ours. Our results differ in that they show labeling of cells in layer $4 \mathrm{~B}$ with only very few filled cells in $4 \mathrm{~A}$, mostly confined to the lower limits of the layer.

There has been no previous report of a projection from V1 to V2 originating from layers 5 and 6 . Other studies have reported the superior temporal sulcus as being the cortical targets of layer 6 (Lund et al., 1975; Maunsell and Van Essen, 1983). The presence in our material of retrograde labeled neurons in layer 5 and upper layer 6 following injections of fluorescent dyes in V2 in our opinion reflects the greater sensitivity of these dyes as retrograde tracers with respect to HRP. Using the sensitive tracer wheat germ agglutinin-conjugated HRP, we recently confirmed that some layer 6 neurons project to $V 2$ and the prelunate gyrus $(H$. Kennedy, J.
Bullier, and C. Dehay, unpublished results). It is worth mentioning that fluorescent dyes also reveal a projection from layer $5 / 6$ in $\mathrm{V} 1$ projecting to V2 in the cat (Bullier et al., 1984b) as well as in the New World monkey, Saimiri (J. Bullier and $\mathrm{H}$. Kennedy, unpublished results). In the cat and macaque, cortical folding is such that $\mathrm{V} 1$ and V2 injections are separated by white matter containing afferents to both areas. However, it is highly improbable that the labeling of layers 5 and 6 (in $V_{1}$ ) in the cat or macaque results from a diffusion of the V2 dye into the underlying white matter, since the cells in lower layer 6, which are known to have axons directed out into the white matter, failed to show retrograde labeling. In Saimiri the absence of cortical fissures means that the injection in V2 is not in ciose proximity to the afferents to $V 1$, so that the possibility of contamination belween injection siles can be discarded. The result in the New World monkey confirms that afferents to V2 originating in layer 6 in $V 1$ are a general feature.

Outside of $\mathrm{V} 1$, corticocortical cells were found predominantly in layers 5 and 6 . In V2, cells projecting to $V 1$ were found in layers $2 / 3$ and $5 \%$, confirming the results of previous studies (Rockland and Pandya, 1979; Lund et al., 1981). The proportion of corticocortical cells in upper layers of the cortex was very much lower in V2 after injection in $V_{1}$ than in $V_{1}$ following a $V_{2}$ injection (20\% and $80 \%$, respectively). In cortical regions which are placed at increasing distance from $\mathrm{V} 1$, the proportion of retrograde labeled cells in lower cortical layers increased and, like other workers, we found that, in the superior temporal sulcus, nearly all of the cells projecting to V1 and V2 belong to layers 5 and 6 (Rockland and Pandya, 1979; Doty, 1983; Weller and Kaas, 1983).

Significance of present results to processing of visual information in the cortex. It has been known for some time that the visual responsiveness of peristriate cortex in the monkey is dependent on cortical projections from V1 (Mishkin, 1966; Schiller and Malpeli, 1977). These connections allow an outflow of activity from area 17 to the circumstriatc cortcx and out toward the inferior temporal and frontal cortex (Kuypers et al., 1965). These connections are reciprocated, so that it is possible to distinguish between rostral-and caudal-directed connections (Kuypers et al., 1965; Rockland and Pandya, 1979). There have been numerous reports that in the primate group, rostral connections originate in the supragranular layers and terminate principally in layer 4 (Cragg, 1969; Spatz et al., 1970; Lund et al., 1975; Martinez-Millan and Hollander, 1975; Van Essen and Zeki, 1978; Wong-Riley, 1978; Rockland and Pandya, 1979) and that caudally directed efferents mostly originate from infragranular layers and terminate outside of layer 4 (Kuypers et al., 1965; Tigges et al., 1973, 1977; Kaas and Lin, 1977; Wong-Riley, 1978). Rockland and Pandya (1979) suggested that this laminar distribution of cortical afterent neurons and their terminals is an indication of the sequence of information processing in cortex and that connections originating in supragranular layers and terminating in layer 4 constitute a feedforward pathway channeling information to cortical areas carrying out a higher order of analysis. Connections arising in the infragranular layers and terminating outside of layer 4 , in contrast, correspond in this scheme to feedback connections, enabling cortical regions of a higher order of analysis to modulate 
lower level cortical areas. This idea has been recently revived by Maunsell and Van Essen (1983), who used the laminar distributions of source neurons and their termination fields to rank the different visual areas of the macaque cortex in a hierarchical order with V1 and V2 on the two lowest levels.

The laminar distribution of labeled neurons that we obtain in prestriate cortex after injections in V1 and V2 generally confirms the conclusions of Rockland and Pandya (1979) and Maunsell and Van Essen (1983) that caudal-directed connections mostly arise from infragranular layers, whereas rostral-directed neurons belong to supragranular layers. Our quantitative estimates of the proportions of infra- and supragranular neurons demonstrate, however, that there are only rare examples of connections arising cxclusively from supraor from infragranular layers. A hierarchical ranking of areas based on cortical connectivity must presumably take this complicating factor into account. One possibility is that hierarchical ranking is made by the relative proportions of infragranular layer neurons in different areas. In other words, one area will have a higher rank than another if its output to that area contains more infragranular layer neurons than does its input. As a consequence of this ranking method, areas on distant hierarchical levels will communicate exclusively via infra and supragranular layer neurons, whereas areas on neighboring levels will communicate with neurons from both sets of layers. The functional significance in terms of information processing of this ranking procedure rests on the presence of distinct physiological properties of neurons in infragranular and supragranular layers of extrastriate cortex. Clearly, these speculations require some electrophysiological testing before the significance of the laminar distribution of corticocortical neurons can be fully understood

A further difficulty in reconciling our results with a strict hierarchical model is the presence in our study of neurons labeled in an extensive region of the cortex which probably includes V3, V3A, V4, and V5 (Zeki, 1978). If the corticocortical connections are always reciprocal as is generally believed in the visual system, (Maunsell and Van Essen 1983; Symonds and Rosenquist 1984), this suggests that V1 projects to all of these areas, as indeed has already been shown by Zeki (1969) and Cragg (1969). Since the hierarchical scheme is founded on the belief that V1 only projects to V2 and MT, the presence of a direct input to these additional areas raises the question of the validity of this scheme. Should all prestriate areas receive a direct input from area 17 , their position in a supposed hierarchical sequence might in fact merely reflect their distance from $\mathrm{V} 1$ on the cortical surface.

Finally, the results of our double-labeling study on the afferent connections raises questions on the conceptual significance which can be attached to the concept of hierarchical levels. V2 is commonly considered as a higher order area than $\mathrm{V} 1$. This stems from the fact that $V 1$ receives the vast majority of LGN afferents and constitutes the main source of input to V2. Our results, however, demonstrate that $\mathrm{V} 1$ and $\mathrm{V} 2$ share a considerable amount of neural information coming from common subcortical and cortical sources and that some of this common information is provided by neurons with a bifurcating axon. This suggests that, even though V2 depends on V1 for its visual input in the intact animal, these two areas will function in unison and receive a great deal of common information. On these grounds $V_{1}$ and $V_{2}$ in the monkey are similar to $V_{1}$ and $\mathrm{V} 2$ in the cat (Bullier et al., 1984a, b), despite the fact that, in the cat, V2 does not depend to a great extent on V1 for its visual activation (Donaldson and Nash, 1975; Dreher and Cottee, 1975; Sherk, 1978). In conclusion, our results point to a different view of the relations between $V 1$ and $V 2$ than those implied by the concept of a hierarchy: neural information is not simply passed on from $\mathrm{V} 1$ to $\mathrm{V} 2$, it is processed in a distributed fashion in a neural net involving $V_{1}, V_{2}$, and the numerous subcortical and cortical structures which are common afferents to these areas.

\section{References}

Barlow, H. B. (1981) Critical limiting factors in the design of the eye and visual cortex. Proc. R. Soc. Lond. (Biol.) 212: 1-34.
Bender, D. B. (1981) Retinotopic organization of macaque pulvinar. J Neurophysiol. 46: 672-693.

Benevento, L. A., and J. H. Fallon (1975) The ascending projections of the superior colliculus in the rhesus monkey (Macaca mulatta). J. Comp. Neurol. 160: 339-362.

Benevento, L. A., and K. Yoshida (1981) The afferent and efferent organization of the lateral geniculo-prestriate pathways in the macaque monkey. J. Comp. Neurol. 203: 455-474

Blasdel, G. G., and J. S. Lund (1983) Termination of afferent axons in macaque striate cortex. J. Neurosci. 3: 1389-1413

Bullier, J. (1985) Axonal bifurcation in the afferents to cortical areas of the visual system. In Visual Neuroscience, Festschrift for P. O. Bishop, J. Pettigrew, W. R. Levick, and K. Sanderson, eds., Cambridge University Press, London, in press.

Bullier, J., and $\mathrm{H}$. Kennedy (1983) Projection of the lateral geniculate nucleus onto cortical area V2 in the macaque monkey. Exp. Brain Res. 53: 168 172 .

Bullier, J., H. Kennedy, and W. Salinger (1984a) Bifurcation of subcortica afferents to visual areas 17,18 and 19 in the cat cortex. J. Comp. Neurol. 228: 309 - 328 .

Bullier, J., H. Kennedy, and W. Salinger (1984b) Branching and laminar origin of projections between visual cortical areas in the cat. J. Comp. Neurol. 228: 329-341.

Connolly, M., and D. C. Van Essen (1984) The representation of the visual field in parvicellular and magnocellular layers of the lateral geniculate nucleus in the macaque monkey. J. Comp. Neurol. 226: 544-564.

Cragg, B. G. (1969) The topography of the afferent projections in the circumstriate visual cortex of the monkey studied by the Nauta method Vision Res. 9: 733-747.

Donaldson, I. M. L., and J. R. G. Nash (1975) The effect of a chronic lesion in cortical area 17 on the visual responses of units in area 18 of the cat J. Physiol. (Lond.) 245: 325-332.

Doty, R. W. (1983) Nongeniculate afferents to striate cortex in macaques. J. Comp. Neurol. 218: 159-173.

Dreher, B., and L. J. Cottee (1975) Visual receptive-field properties of cells in area 18 of cat's cerebral cortex before and after acute lesions in area 17. J. Neurophysiol. 38: 735-750.

Fisken, R. A. L. J. Garey, and T. P. S. Powell (1975) The intrinsic, association and commissural connections of area 17 of the visual cortex. Philos. Trans R. Soc. Lond. (Biol.) 272: 487-536.

Fries, $W$. (1981) The projection from the lateral geniculate nucleus to the prestriate cortex of the macaque monkey. Proc. R. Soc. Lond. (Biol.) 213 . $73-80$

Gattass, R., C. G. Gross, and J. H. Sandell (1981) Visual topography of V2 in the macaque. J. Comp. Neurol. 201: 519-539

Geisert, E. E., Jr. (1980) Cortical projections of the lateral geniculate nucleus in the cat. J. Comp. Neurol. 190:793-812.

Hollander, $H_{\text {., }}$ and $H$. Vancgas (1977) The projection from the dorsal lateral geniculate nucleus onto the visual cortex in the cat. A quantitative study with horseradish peroxidase. J. Comp. Neurol. 173: 519-536.

Humphrey, A. L., M. Sur, D. J. Uhlrich, and S. M. Sherman (1985) Projection patterns of individual $X$ - and $Y$-cell axons from the lateral geniculate nucleus to cortical area 17 in the cat. J. Comp. Neurol. 233: 159-189.

Kaas, J. H. (1980) A comparative survey of visual cortex organization in mammals. In Comparative Neurology of the Telencephalon, S. O. E. Ebbesson, ed., pp. 483-502, Plenum Press, New York

Kaas, J. H., and C. S. Lin (1977) Cortical projections in area 18 on owl monkeys. Vision Res. 17: 739-741.

Keizer, K., H. G. J. M. Kuypers, A. M. Huisman, and O. Dann (1983) Diamidino yellow dihydrochloride (DY:2HCl): A fluorescent retrograde neu ronal tracer which migrates only very slowly out of the cell and can be uscd in combination with $\mathrm{TB}$ and $\mathrm{FB}$ in double labcling experiments. Exp. Brain Res. 51: 179-191.

Kimura, M., T. Shiida, K. Tanaka, and K. Toyama (1980) Three classes of area 19 corlical cells of the cal classified by their neuronal connectivity and photic responsiveness. Vision Res. 20: 69-77

Kuypers, H. G. J. M., M. K. Szwarcbart, M. Mishkin, and H. E. Rosvold (1965) Occipitotemporal corticocortical connections in the rhesus monkey. Exp. Neurol. 11: 245-262.

Lund, J. S. (1973) Organization of neurons in the visual cortex, area 17, of the monkey (Macaca mulatta). J. Comp. Neurol. 147: 455-496.

Lund, J. S., R. D. Lund, A. E. Hendrickson, A. H. Bunt, and A. F. Fuchs (1975) The origin of efferent pathways from the primary visual cortex of the macaque monkey as shown by retrograde transport of horseradish peroxidase. J. Comp. Neurol. 164: 287-304.

Lund, J. S., A. E. Hendrickson, M. Г. Ogren, and E. A. Tobin (1981) 
Anatomical organization of primate visual cortical area VII. J. Comp. Neurol. 202: $19-45$.

Maciewicz, R. J. (1975) Thalamic afferents to areas 17, 18 and 19 of the cat cortex traced with horseradish peroxidase. Brain Res. 84: 308-312.

Malpeli, J. G., and F. H. Baker (1975) the representation of the visual field in the lateral geniculate nucleus of Macaca mulatta. J. Comp. Neurol. 161: 569-594.

Martinez-Millan, L., and H. Hollander (1975) Cortico-cortical projections from striate cortex of the squirrel monkey (Saimiri sciureus). A radioautographic study. Brain Res. 83: 405-417.

Maunsell, J. H. R., and D. C. Van Essen (1983) The connections of the middle temporal visual area (MT) and their relationship to a cortical hierarchy in the macaque monkey. J. Neurosci. 3: 2563-2586.

Mishkin, M. (1966) Visual mechanisms beyond the striate cortex. In Frontiers in Physiological Psychology, R. Russell, ed., pp. 93-119, Academic Press, New York

Mizuno, N., K. Uchida, S. Nomura, Y. Nakamura, T. Sugimoto, and M. Uemura-Sumi (1981) Extrageniculate projections to the visual cortex in the macaque monkey: An HRP study. Brain Res. 212: 454-459.

Ogren, M. P., and A. Hendrickson (1976) Pathways between striate cortex and subcortical regions in Macaca mulatta and Saimiri sciureus: Evidence for a reciprocal pulvinar connection. Exp. Neurol. 53: 780-800.

Partlow, G. D., M. Colonnier, and J. Szabo (1977) Thalamic projections of the superior colliculus in the rhesus monkey Macaca mulatta. A light and electron microscopic study. J. Comp. Neurol. 171: 285-318.

Rezak, M., and L. A. Benevento (19/9) A comparison of the organization of the projections of the dorsal lateral geniculate nucleus, the inferior pulvinar and adjacent lateral pulvinar to primary visual cortex (area 17) in the macaque monkey. Brain Res. 167: 19-40.

Riche, D., and J. Lanoir (1978) Some claustro-cortical connections in the cat and baboon as studied by retrograde horseradish peroxidase transport. J. Comp. Neurol. 177: 435-444.

Rockland, K. S., and'D. N. Pandya (1979) Laminar origins and terminations of cortical connections to the occipilal lobe in the rhesus monkey. Brain Res. 179: 3-20.

Schiller, P. H., and J. G. Malpeli (1977) The effect of striate cortex cooling on area 18 cells in the monkey. Brain Res. 126: 366-369.

Sherk, H. (1978) Area 18 cell responses in cat during reversible inactivation of area 17. J. Neurophysiol. 41: 204-215

Spatz, W. B., and S. Grabig (1983) Reduced fading of fast blue fluorescence in the brain of the guinea-pig by treatment with sodium nitroprusside. Neurosci. Lett. 38: 1-4.

Spatz, W. B., J. Tigges, and M. Tigges (1970) Subcortical projections, cortical associations, and some intrinsic interlaminar connections of the striate cortex in the squirrel monkey (Saimiri). J. Comp. Neurol. 140: 155-174.

Symonds, L. L., and A. C. Rosenquist (1984) Corticocortical connections among visual areas in the cat. J. Comp. Neurol. 229: 1-38.

Tigges, J., W. B. Spatz, and M. Tigges (1973) Reciprocal point-to-point connections between parastriate and striate cortex in the squirrel monkey (Saimiri). J. Comp. Neurol. 148: 481-490.

Tigges, J., M. Tigges, and A. A. Perachio (1977) Complementary laminar terminations of afferents to area 17 originating in area 18 and in the lateral geniculate nucleus in squirrel monkey. J. Comp. Neurol. 176: 87-100.

Trojanowski, J. Q., and S. Jacobson (1977) The morphology and laminar distribution of corticopulvinar ncurons in the rhesus monkcy. Exp. Brain Res. 28: 51-62

Tusa, R. J., L. A. Palmer, and A. C. Rosenquist (1981) Multiple cortical areas. Visual field topography in the cal. In Cortical Sensory Organizalion. Vol. 2: Multiple Visual Areas, L. N. Woolsey, ed. pp. 1-31, Humana Press, Clifton, NJ.

Ungerleider, L. G., T. W. Galkin, and M. Mishkin (1983) Visuotopic organization of projections from striate cortex to inferior and lateral pulvinar in rhesus monkey. J. Comp. Neurol. 217: 137-157.

Updyke, B. V. (1983) A reevaluation of the functional organization and cytoarchitecture of the feline lateral posterior complex, with observations on adjoining cell groups. J. Comp. Neurol. 219: 143-181.

Van Essen, D. C. (1979) Visual areas of the mammalian cerebral cortex. Annu. Rev. Neurosci. 2: 227-263.

Van Essen, D. C., and S. M. Zeki (1978) The topographic organization of rhesus monkey prestriate cortex. J. Physiol. (Lond.) 277: 193-226.

Van Essen, D. C., J. H. R. Maunsell, and J. L. Bixby (1981) The middle lemporal visual area in the macaque: Myeloarchitecture, connections, functional properties and topographic organization. J. Comp. Neurol. 199: 293-326.

Weller, R. E., and J. H. Kaas (1983) Retinotopic patterns of connections of area 17 with visual areas VII and MT in macaque monkeys. J. Comp. Neurol. 220: 253-279.

Wong-Riley, M. (1978) Reciprocal connections between striate and prestriate cortex in the squirrel monkey as demonstrated by combined peroxidase histochemistry and autoradiography. Brain Res. 147: 159-164.

Yukie, M., and E. Iwai (1981) Direct projection from the dorsal lateral geniculate nucleus to the prestriate cortex in macaque monkeys. J. Comp. Neurol. 201: 81-97.

Zeki, S. M. (1969) Representation of central visual fields in prestriate cortex of monkey. Brain Res. 14: 271-291.

Zeki, S. M. (1978) Functional specialisation in the visual cortex of the rhesus monkey. Nature 274: 423-428. 